\title{
Knockdown of EphB1 receptor decreases medulloblastoma cell growth and migration and increases cellular radiosensitization
}

\author{
Shilpa Bhatia1,*, Nimrah A. Baig ${ }^{2, *}$ Olga Timofeeva ${ }^{2}$, Elena B. Pasquale ${ }^{3}$, \\ Kellen Hirsch ${ }^{1}$, Tobey J. MacDonald ${ }^{4}$, Anatoly Dritschilo ${ }^{2,7}$, Yi Chien Lee ${ }^{2}$, \\ Mark Henkemeyer ${ }^{5}$, Brian Rood ${ }^{6}$, Mira Jung ${ }^{2}$, Xiao-Jing Wang ${ }^{8}$, Marcel Kool ${ }^{9}$, \\ Olga Rodriguez ${ }^{2, *}$, Chris Albanese ${ }^{2,10, *}$, Sana D. Karam ${ }^{1,2, *}$ \\ ${ }^{1}$ Department of Radiation Oncology, University of Colorado Denver, Anschutz Medical Campus, Aurora, CO 80045, USA \\ ${ }^{2}$ Department of Oncology, Lombardi Comprehensive Cancer Center, Georgetown University Medical Center, Washington, DC \\ 20057, USA \\ ${ }^{3}$ Sanford-Burnham Medical Research Institute, La Jolla, CA 92037, USA \\ ${ }^{4}$ Department of Pediatrics, Emory University School of Medicine, Atlanta, GA 30322, USA \\ ${ }^{5}$ Department of Developmental Biology, University of Texas Southwestern Medical Center, Dallas, TX 75390, USA \\ ${ }^{6}$ Children's National Medical Center, Washington DC 20010, USA \\ ${ }^{7}$ Georgetown University Hospital, Washington, DC, 20007, USA \\ ${ }^{8}$ Department of Pathology, University of Colorado Denver, Anschutz Medical Campus, Aurora, CO 80045, USA \\ ${ }^{9}$ Division of Pediatric Neurooncology, German Cancer Research Center DKFZ, Heidelberg, Germany \\ ${ }^{10}$ Department of Pathology, Georgetown University School of Medicine, Washington, DC 20057, USA \\ *These authors have contributed equally to this work
}

Correspondence to:

Sana D. Karam, e-mail: sana.karam@ucdenver.edu

Keywords: Eph, medulloblastoma, ATM, cell cycle, radiosensitization

Received: December 05, $2014 \quad$ Accepted: February 11, 2015

Published: March 30, 2015

\section{ABSTRACT}

The expression of members of the Eph family of receptor tyrosine kinases and their ephrin ligands is frequently dysregulated in medulloblastomas. We assessed the expression and functional role of EphB1 in medulloblastoma cell lines and engineered mouse models. mRNA and protein expression profiling showed expression of EphB1 receptor in the human medulloblastoma cell lines DAOY and UW228. EphB1 downregulation reduced cell growth and viability, decreased the expression of important cell cycle regulators, and increased the percentage of cells in G1 phase of the cell cycle. It also modulated the expression of proliferation, and cell survival markers. In addition, EphB1 knockdown in DAOY cells resulted in significant decrease in migration, which correlated with decreased $\beta 1$-integrin expression and levels of phosphorylated Src. Furthermore, EphB1 knockdown enhanced cellular radiosensitization of medulloblastoma cells in culture and in a genetically engineered mouse medulloblastoma model. Using genetically engineered mouse models, we established that genetic loss of EphB1 resulted in a significant delay in tumor recurrence following irradiation compared to EphB1expressing control tumors. Taken together, our findings establish that EphB1 plays a key role in medulloblastoma cell growth, viability, migration, and radiation sensitivity, making EphB1 a promising therapeutic target.

\section{INTRODUCTION}

The erythropoietin-producing hepatocellular carcinoma (Eph) receptors constitute the largest family of receptor tyrosine kinases and are comprised of 14 different receptors and their cognate ligands, the ephrins $[1,3]$. Eph receptors are divided into two classes: the EphA receptors, which interact preferentially with glycosylphosphatidylinositol (GPI)-linked ephrin A ligands; and the EphB receptors, which bind 
transmembrane ephrin B ligands. The transmembrane anchorage of ephrin B ligands permits both forward signaling, through the Eph receptor-expressing cell, and reverse signaling, through the ephrin-expressing cell. During mammalian development, members of the Eph/ ephrin families are known to fulfill important roles in tissue formation and organization including axon guidance, synaptogenesis and pattern formation [1]. Given their importance in normal development, it is not surprising that the deregulation of normal Eph/ephrin signaling is involved in tumorigenesis [2, 3], with recent reports focusing on the effects of Eph/ephrin system on cell adhesion, migration, proliferation, and angiogenesis $[4,5]$.

Medulloblastoma is a primitive neuroectodermal tumor arising from granule neuron precursors in the cerebellum or from neural stem cells of the rhombic lip. These highly aggressive tumors are among the most frequently diagnosed malignant brain tumors in children. A combination of surgery, radiotherapy, and chemotherapy has contributed to improved treatment outcomes, resulting in a $70-80 \%$ five-year disease-free survival rate [6]. Still, the mortality rate for patients with medulloblastoma remains significant and recurrence is observed in the clinic, often due to cancer cell resistance to radiation therapy. Moreover, there are significant neurological, cognitive, endocrinological, and social sequelae resulting from current chemotherapy and radiotherapy regimens. In light of this prognosis, significant efforts are underway to develop more effective and less toxic treatments for medulloblastoma patients.

Although little is known about the role of the Eph/ ephrin system in medulloblastoma, recent studies have implicated Eph receptors and ephrins as potential players in medulloblastoma tumor progression. For example, overexpression and activation of EphB2, a receptor closely related to EphB1, in medulloblastoma cell lines has been shown to reduce cell adhesion and enhance invasion in vitro [7]. Gene expression analyses of the DAOY medulloblastoma cell line further established that EphB1 is highly upregulated in migrating medulloblastoma cells, compared to noninvasive tumor cells at the primary tumor site [8].

The ATM gene represents an important component of DNA damage pathways. In our previous studies, we established that mutations in ATM resulted in hypersensitivity to radiation in fibroblasts derived from a patient with mutated ATM [9], and using these cells, we identified molecules regulated by ATM in order to develop targeted radiosensitizers [9]. Furthermore we showed that genetic repair of ATM via its expression in the ATM-deficient fibroblast cell line, AT5BIVA, resulted in increased cellular radiation-resistance [10]. Importantly, a greater than 10 fold increase in EphB1 expression was found in the ATM-proficient ATCL8 cells (derived from AT5BIVA) compared to the ATM-deficient AT5BIVA cells [10], suggesting that EphB1 may be responsible, at least in part, for the observed increase in radiation resistance.
Despite these important findings, no additional studies have been reported to date that directly investigate the role of EphB1 in medulloblastoma tumorigenesis. Since EphB1 plays a key function in the development and progression of other cancers, such as glioma, esophageal, colorectal and gastric cancers [11-15], we sought to better define the role of this receptor in medulloblastoma. Using both human medulloblastoma cell lines and genetically engineered mouse models, we investigated the role of EphB1 in medulloblastoma cell growth, migration, and radiosensitization. Herein, we show that knockdown of EphB1 decreased medulloblastoma cell growth and migration, and increased the radiosensitivity of the medulloblastoma cell line in vitro. In addition, we developed a new in vivo model of EphB1 function in medulloblastoma, by crossing the previously described ND2-SmoA1 preclinical medulloblastoma mouse [16-18] with our EphB1 knockout mouse model [19, 20]. Using this new model, we show that the genetic loss of $E p h B 1$ results in a significant delay in tumor recurrence following radiotherapy. Collectively, our results are consistent with the hypothesis that upregulation of EphB1 contributes to the aggressive and invasive nature of medulloblastoma. To our knowledge, this study represents the first exploration into the functional role of EphB1 gene in medulloblastoma cell migration, growth, and radiosensitization. Thus, future strategies involving targeted inhibition of EphB1 receptor may hold therapeutic value for the treatment of medulloblastoma.

\section{RESULTS}

\section{EphB1 is expressed in medulloblastoma tumors}

The expression of EphB1 receptor varies widely in medulloblastoma [8]. We evaluated the expression of EphB1 in a human medulloblastoma cell line, DAOY, and found EphB1 to be expressed at both the mRNA and protein level (Figure 1A, 1B). To assess the role of EphB1 in medulloblastoma, we next attempted to knockdown EphB1 expression using siRNA approach. DAOY cells were transfected with either EphB1 siRNA or a control, nonspecific siRNA (Ns-siRNA). EphB1 expression was analyzed at the mRNA level at 24, 48, and $72 \mathrm{~h}$ post-transfection. We found that EphB1 mRNA levels were reduced to $18 \%$ or less by $24 \mathrm{~h}$ in the EphB1knockdown group compared to the control, non-specific siRNA (Ns-siRNA) transfected group, with optimal knockdown efficiency observed at $72 \mathrm{~h}$ post-transfection (Figure 1A). Additionally, there was a substantial reduction in the levels of EphB1 protein by western blot analysis of EphB1-knockdown DAOY cells compared to control transfectants (Figure 1B). The results were also replicated in another medulloblastoma cell line, UW228 (Supplementary Figure 1A). Since western blot analysis confirmed an appreciable reduction in EphB1 protein levels, we conducted a series of experiments to determine 


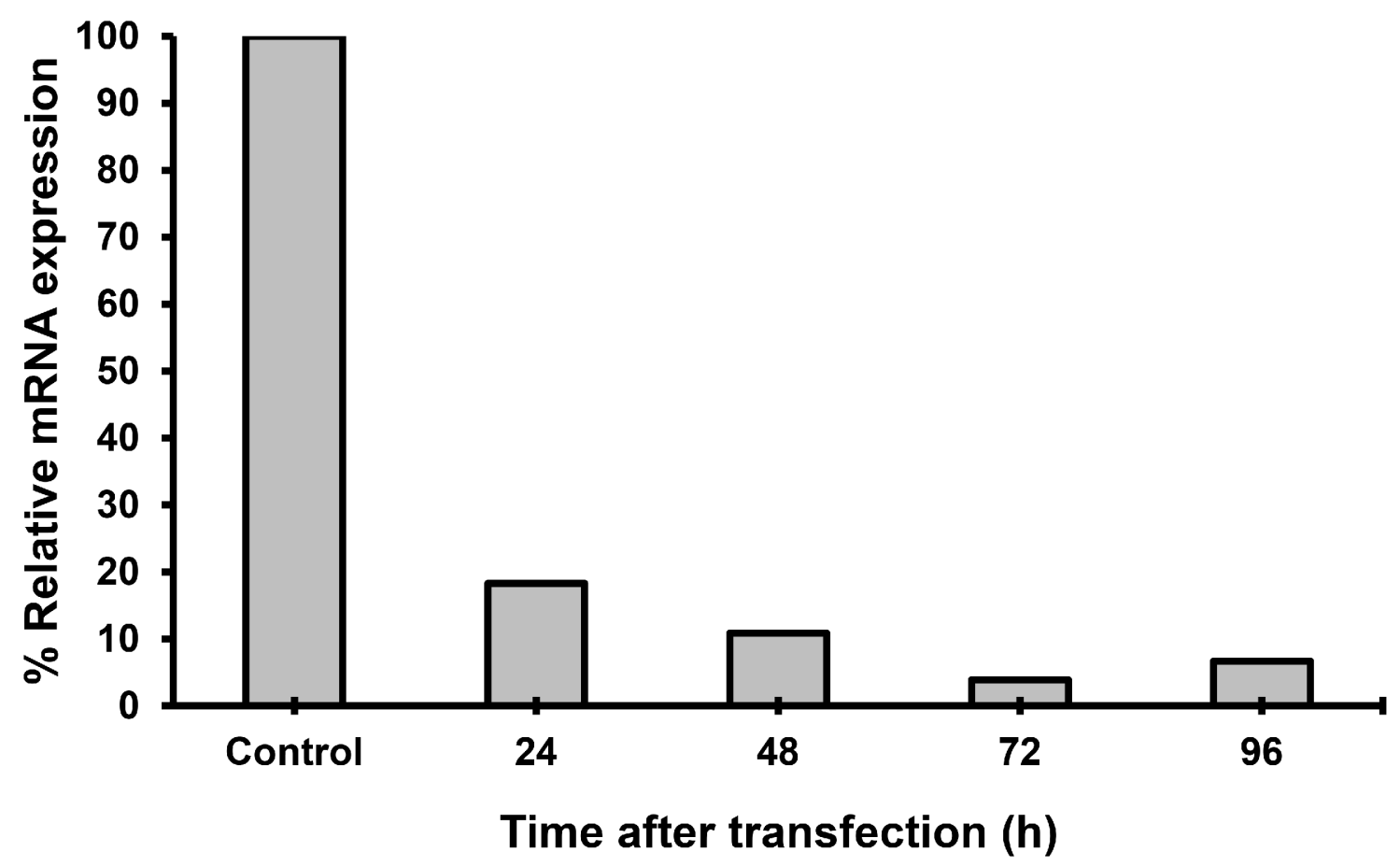

B

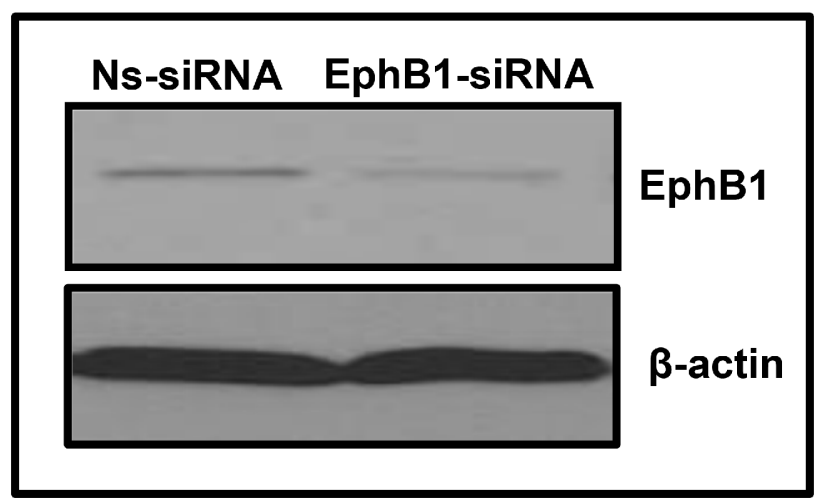

Figure 1: EphB1 is effectively knocked down in DAOY medulloblastoma cells. (A) EphB1 mRNA level is dramatically reduced upon transfection of DAOY cells with EphB1-siRNA. (B) EphB1 expression is detected by western blotting in DAOY cells and is decreased upon transfection with EphB1-targeting siRNA vs. control non-specific siRNA (Ns-siRNA).

whether EphB1 downregulation affects cell viability, cell cycle progression, migration, and radiosensitivity.

\section{Knockdown of EphB1 receptor reduces cell growth and viability}

We investigated the effect of EphB1 knockdown on cell growth and viability using total cell count and an MTT assay. DAOY cells transfected with EphB1-targeting
siRNA and serum-starved for $24 \mathrm{~h}$ were stimulated to grow by addition of serum for $48 \mathrm{~h}$. EphB1-siRNA- transfected cells showed a significant reduction in the number of live cells as determined by trypan blue exclusion, following knockdown of EphB1 receptor (Figure 2A). Additionally, the MTT assays showed a significant reduction in cell growth of about 26\% in EphB1-knockdown cells compared to non-specific siRNA (Ns-siRNA) control transfected cells (Figure 2B). 
A

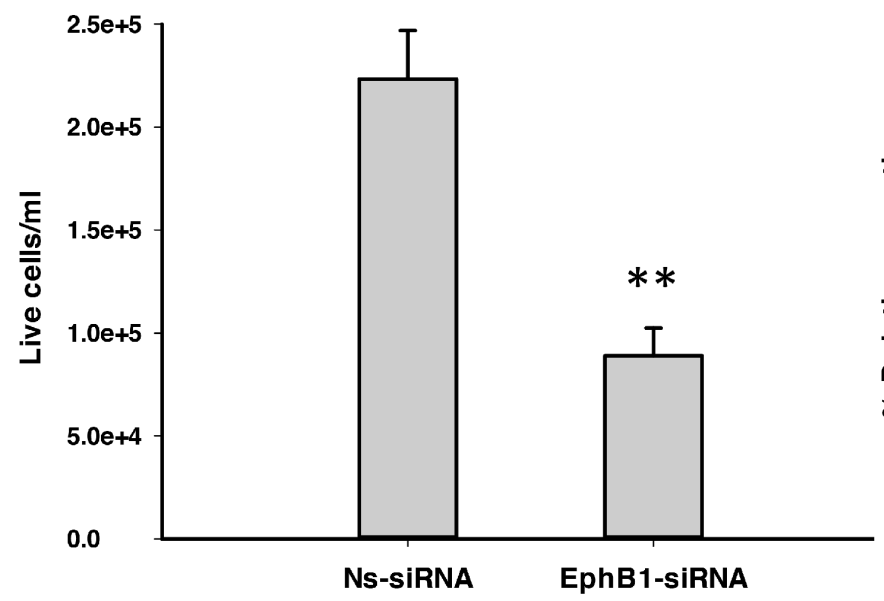

B

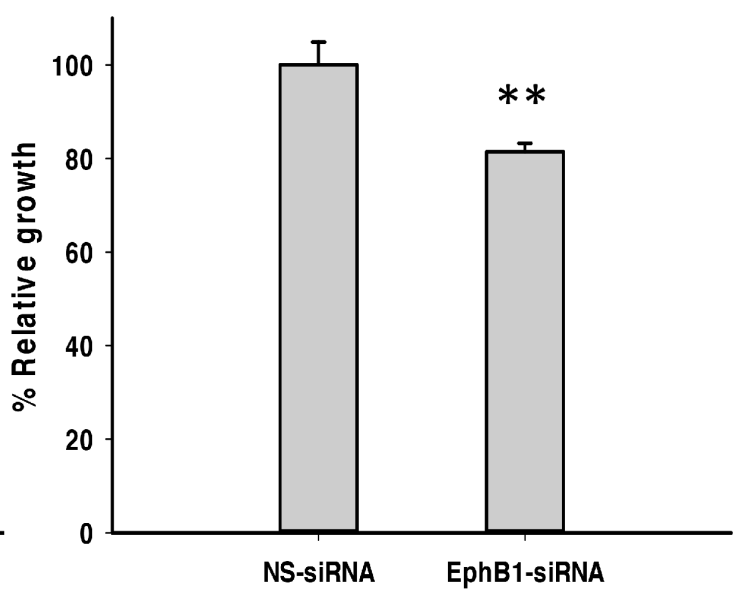

\section{C}

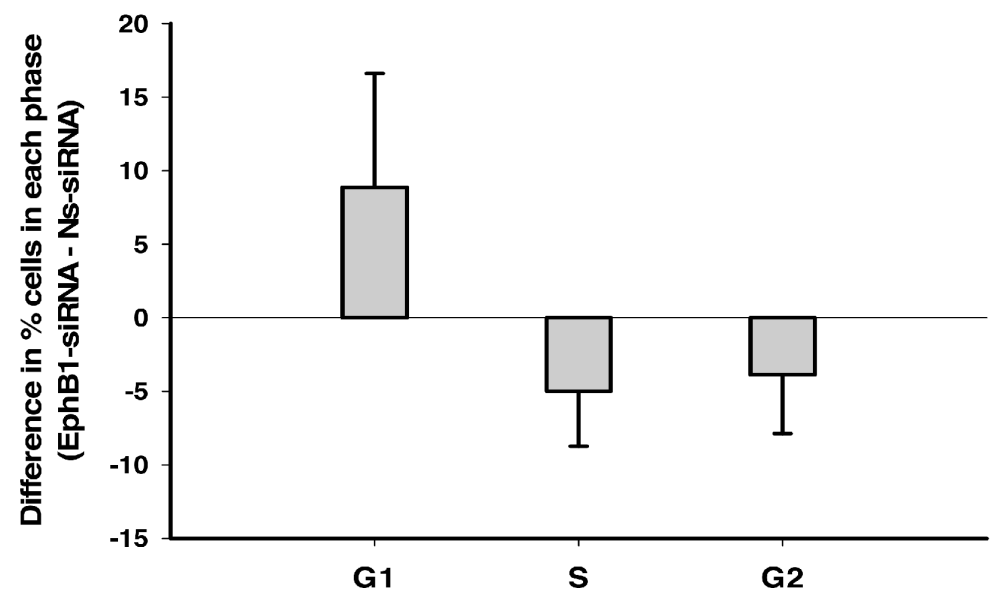

Figure 2: Knockdown of EphB1 reduces medulloblastoma cell viability and cell growth, and alters cell cycle progression. (A) EphB1 knockdown results in a significant decrease in live cell count as assessed by the trypan blue dye exclusion assay $(n=3, * p \leq 0.01 ; * *<0.001)$. (B) Knockdown of EphB1 results in an approximately $26 \%$ decrease in cell growth as quantified by MTT assay $\left(n=2,{ }^{*} p<0.001\right)$. (C) Knockdown of EphB1 increases percentage of cells in G1 phase $(n \geq 2)$. Data shown are average \pm standard error from independent experiments. Normalized values are shown in Figure 2B.

\section{Knockdown of EphB1 receptor inhibits cell cycle progression}

We next sought to determine whether EphB1 knockdown affects cell cycle progression. DAOY cells were transfected, serum-starved and then stimulated by addition of serum as above. Cell cycle distribution was analyzed by flow cytometry as previously described [21-23]. A higher percentage of cells in the G1 phase were observed in EphB1knockdown cells compared to the non-specific siRNA (Ns-siRNA) transfected cells (Figure 2C). Similar results were obtained with another well-studied medulloblastoma cell line, UW228, where EphB1 knockdown showed an approximately $11 \%$ increase in the percentage of cells in the G1 phase as compared to the control non-specific siRNA (Ns-siRNA) transfected group (Supplementary Figure 1B). 
EphB1 knockdown modulates cell cycle, cell proliferation, and survival proteins

We next investigated the mechanism underlying the role of EphB1 in DAOY cells by evaluating the expression of proteins known to play a role in cell cycle progression and cell survival. We found that EphB1 downregulation resulted in a decrease in the levels of cyclin $\mathrm{E}$, phosphorylated E2F1 (p-E2F1), phosphorylated Chk2 (p-Chk2), and phosphorylated $\mathrm{Rb}(\mathrm{p}-\mathrm{Rb}$ ) (Figure 3). We also evaluated the levels of PCNA, a proliferation marker, and phosphorylated Akt, a protein whose phosphorylation promotes cell survival. We found that levels of both proteins decreased following EphB1 knockdown (Figure 3). Total AKT levels were also decreased in EphB1-siRNA treated cells (Figure 3). In view of the fact that Eph receptors are known to functionally interact with other tyrosine kinase receptors to promote malignant cell behavior [24], we also analyzed the levels of phosphorylated epidermal growth factor receptor (p-EGFR) and total EGFR and found that p-EGFR and EGFR levels were reduced in the EphB1 knockdown cells (Figure 3).

\section{Knockdown of EphB1 receptor decreases migration}

As EphB1 has been reported to promote migration and chemotaxis in several systems $[25,26]$, we next investigated the impact of EphB1 knockdown on medulloblastoma cells in an electrical impedance-based migration assay. We transiently transfected DAOY cells with the EphB1-targeting siRNA as described above and evaluated the effects of EphB1 knockdown on cell migration post-transfection.

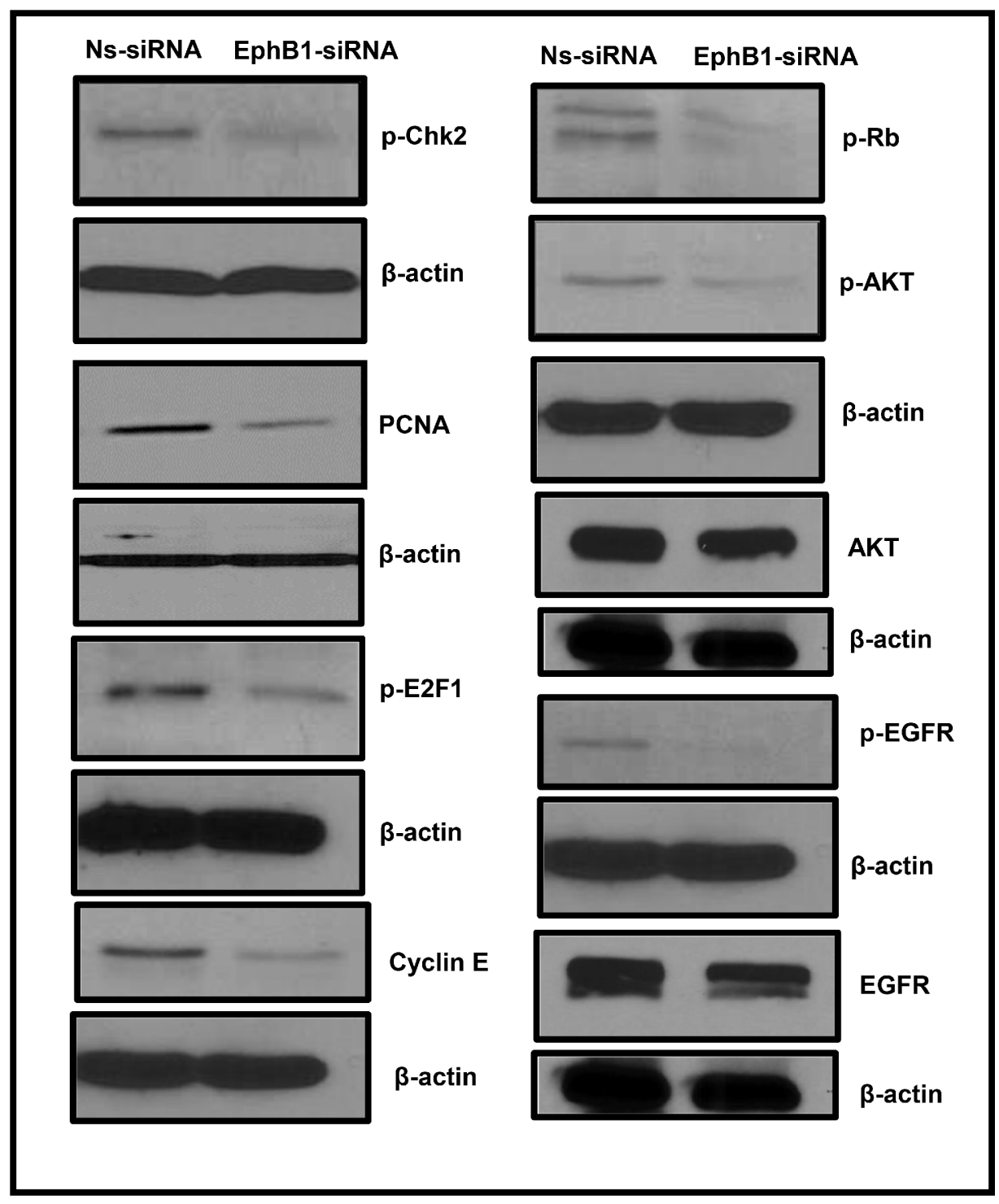

Figure 3: EphB1 knockdown modulates the expression of cell cycle, proliferation, cell survival proteins. Changes were observed in the expression of p-Chk-2, PCNA, p-E2F1, p-Rb, p-AKT, AKT, cyclin E, p-EGFR, and EGFR proteins following EphB1 receptor knockdown compared to the non-specific siRNA (Ns-siRNA) treatment in DAOY cells. 
Compared to control transfectants, knockdown of EphB1 resulted in a 51\% decrease in migration after $21 \mathrm{~h}$ (Figure 4A). We further investigated the role of EphB1 on migration by evaluating the expression of molecules involved in cell adhesion and migration by western blot analysis. EphB1 knockdown resulted in decreased expression of $\beta 1$-integrin and decreased levels of phosphorylated Src while levels of total Src remained constant (Figure 4B).

\section{Knockdown of EphB1 enhances radiosensitization in ATM-proficient fibroblast cells}

Savitsky et al. have found ATM to be a critical regulatory molecule that recognizes DNA damage and activates cellular signaling pathways to protect the genome [27]. Mutations in ATM lead to hypersensitivity to ionizing radiation [28]. To investigate whether EphB1 plays a role in radiation resistance, we knocked down EphB1 in ATM-proficient ATCL8 cells, exposed the cells to a single dose of 2,4 , or 6 Gy of radiation, and performed clonogenic survival assays. Decreased EphB1 expression was accompanied by a significant increase in sensitivity of ATCL8 cells to irradiation (Figure 5). The dose enhancement ratio $\left(\mathrm{D}_{0}\right.$ value) for non-specific siRNA (Ns-siRNA) group was found to be 1.541 in the clonogenic survival assay. For EphB1-siRNA treated group, $\mathrm{D}_{0}$ value was reduced to 1.201 .

\section{Knockdown of EphB1 receptor sensitizes medulloblastoma cells to ionizing radiation}

To investigate whether EphB1 also plays a role in radiation sensitivity, we compared the responses of the EphB1-knockdown vs. control siRNA in DAOY cells. Using a single dose of $10 \mathrm{~Gy}$ of ionizing radiation, cell growth was determined at $96 \mathrm{~h}$ post transfection using an MTT assay. The percentage of cell growth was reduced by approximately $26 \%$ in the EphB1 knockdown cells vs. the non-specific siRNA (Ns-siRNA)-treated DAOY cells (Figure 6). Furthermore, cell growth was reduced by approximately $32 \%$ in the irradiated EphB1 knockdown cells (Figure 6). In addition, analysis of cell cycle profiles by flow cytometry in DAOY cells indicated that knockdown of EphB1 expression enhanced the percentage of cells in G1 phase in both non-irradiated and irradiated (10 Gy) samples at both $48 \mathrm{~h}$ and $72 \mathrm{~h}$ post-irradiation, with a more dramatic effect observed at $72 \mathrm{~h}$ (Figure 7 ).

\section{Knockdown of EphB1 receptor does not radiosensitize medulloblastoma cells by apoptosis}

To further investigate the mechanism by which EphB1 knockdown enhances cellular radiosensitization, we evaluated the role of EphB1 downregulation in triggering apoptosis in DAOY cells. Following EphB1 receptor knockdown and exposure of cells to 10 Gy ionizing radiation, we used Annexin V/propidium iodide (PI) staining to detect a subpopulation of cells undergoing apoptosis. Our data indicate that neither knockdown of EphB1 nor ionizing radiation exposure resulted in a significant increase in the percentage of cells undergoing apoptosis compared to the non-specific siRNA (Ns-siRNA) treatment (Supplementary Figure 2). We further determined the expression of classical apoptotic markers following treatment of DAOY cells with EphB1-siRNA and control Ns-siRNA. Our results suggest that EphB1 knockdown does not induce PARP cleavage in DAOY cells (Supplementary Figure 3). Further, we did not observe any changes in the levels of pro- and anti-apoptotic markers such as Bax and Bcl-XL (Supplementary Figure 3) in the EphB1-siRNA vs. control Ns-siRNA treated cells.

\section{Loss of EphB1 expression enhances radiosensitization in vivo}

To examine the possible effects of EphB1 on radiosensitivity in vivo, we generated a genetically engineered EphB1 knockout mouse medulloblastoma model $\left(E p h B 1^{-1-} S m o\right)$ by crossing the transgenic ND2-SmoA1 medulloblastoma line [17] with our mice deleted of EphB1 $[19,20]$. Gender-matched littermate $E p h B 1^{+/+}$Smo mice were used as controls. Tumor development was assessed by MRI as previously described $[16,18]$ from postnatal day 23 to 12 months of age, or until the mice began displaying symptoms such as ataxia, decreased motor and coordination functions, megalocephaly, hunching, and weight loss. Longitudinal MRI imaging was conducted to delineate the tumors (Figure $8 \mathrm{~A})$. A total of 44 mice were imaged and $128 \mathrm{MRI}$ images were obtained. Once the tumors reached $200-300 \mathrm{~mm}^{3}$, the tissues were harvested, minced, and equivalent numbers of tumor cells were mixed with matrigel and subcutaneously implanted in the mid-dorsal region of the nude mice just rostral to the tail. Once palpable tumors formed, the mice were randomized into four different groups. One group each from the $E p h B 1^{-/-} S m o$ and $E p h B 1^{+/+} S m o$ cohorts were used as non-irradiated controls while the other two groups of mice were treated with fractionated ionizing radiation $(5 \mathrm{~Gy} /$ day $\times$ 4 doses). Tumor volumetric growth kinetics before, during, and after radiation treatment were quantified using caliper measurements.

While the loss of EphB1 did not significantly affect tumor growth in the control animals (data not shown), allografted tumors from $E p h B 1^{-1-} S m o$ mice exhibited a three-fold delay in tumor recurrence after fractionated ionizing radiation compared to allografts harvested from EphB1 $1^{+/+}$Smo controls (Figure 8B).

\section{DISCUSSION}

Aberrant Eph/ephrin signaling has been implicated in a wide variety of human cancers including medulloblastoma [29]. Accumulating evidence suggests a role of Eph receptors 
A

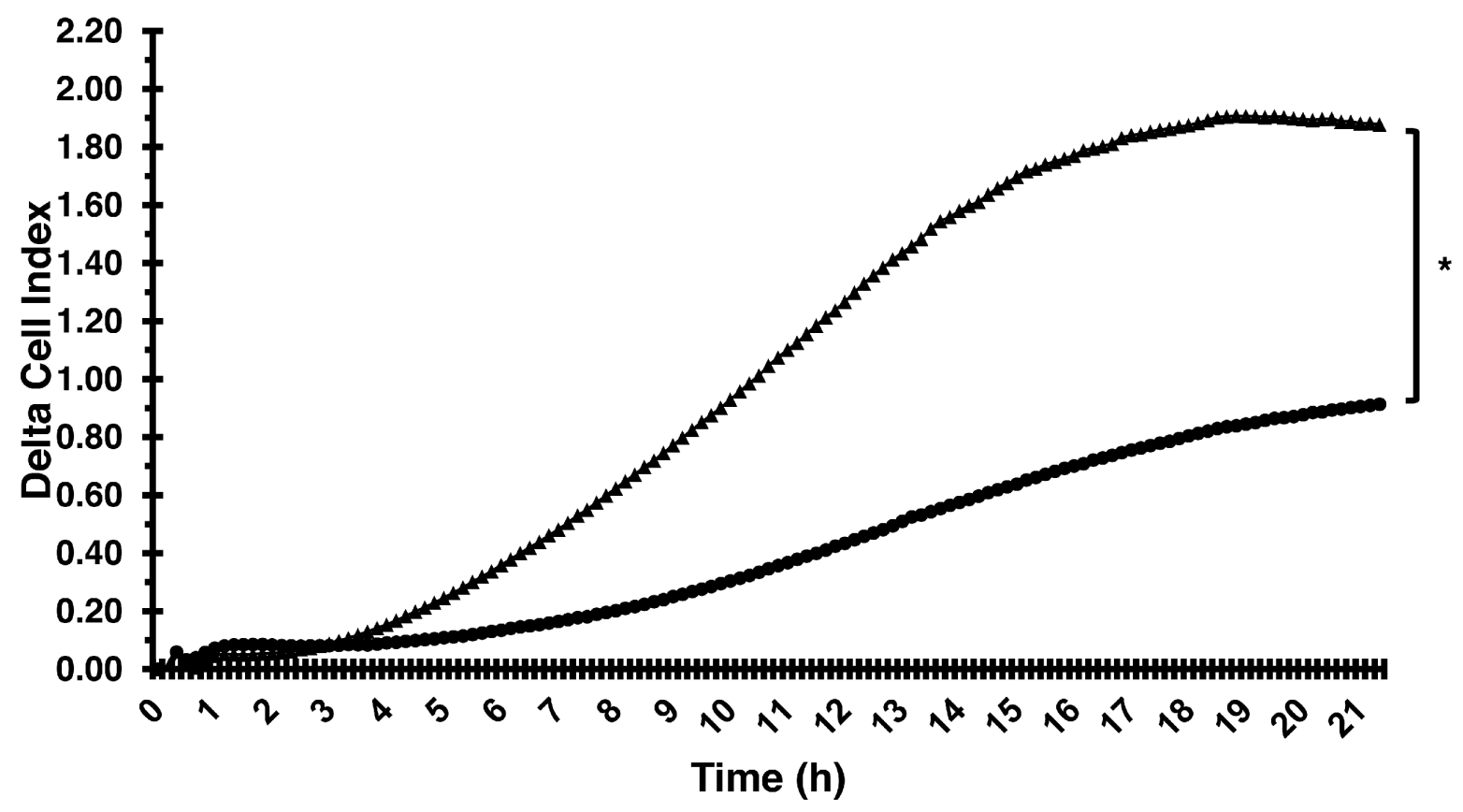

- Ns-siRNA

- EphB1-siRNA

B

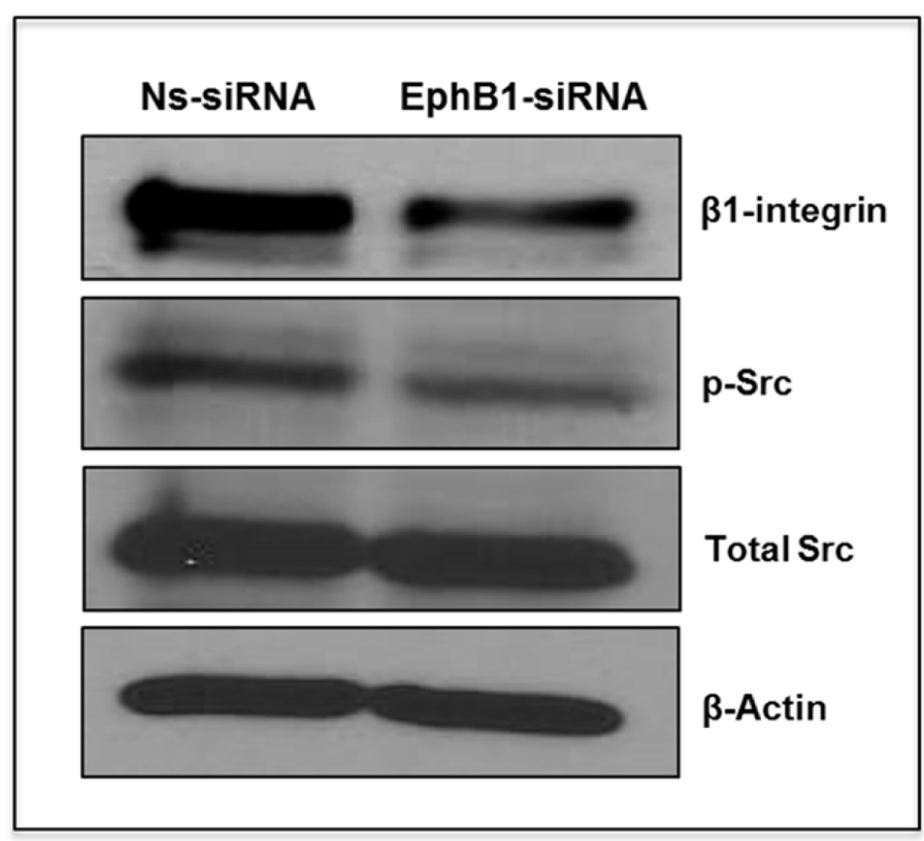

Figure 4: Knockdown of EphB1 receptor reduces medulloblastoma cell migration. (A) A transwell chamber using electrical impedance measurements for cell migration was used. Cell index values represent changes in electrical impedance across the membrane separating the upper and lower chambers, and correlates directly to the number of cells that have migrated into the lower chamber. Background migration was subtracted to obtain delta cell index values. Knockdown of EphB1 decreases the migratory response on average by $51 \%(* p<0.01)$ compared to control non-specific siRNA (Ns-siRNA) transfection. (B) Knockdown of EphB1 results in decreased expression of $\beta 1$-integrin and $\mathrm{p}$-Src. 


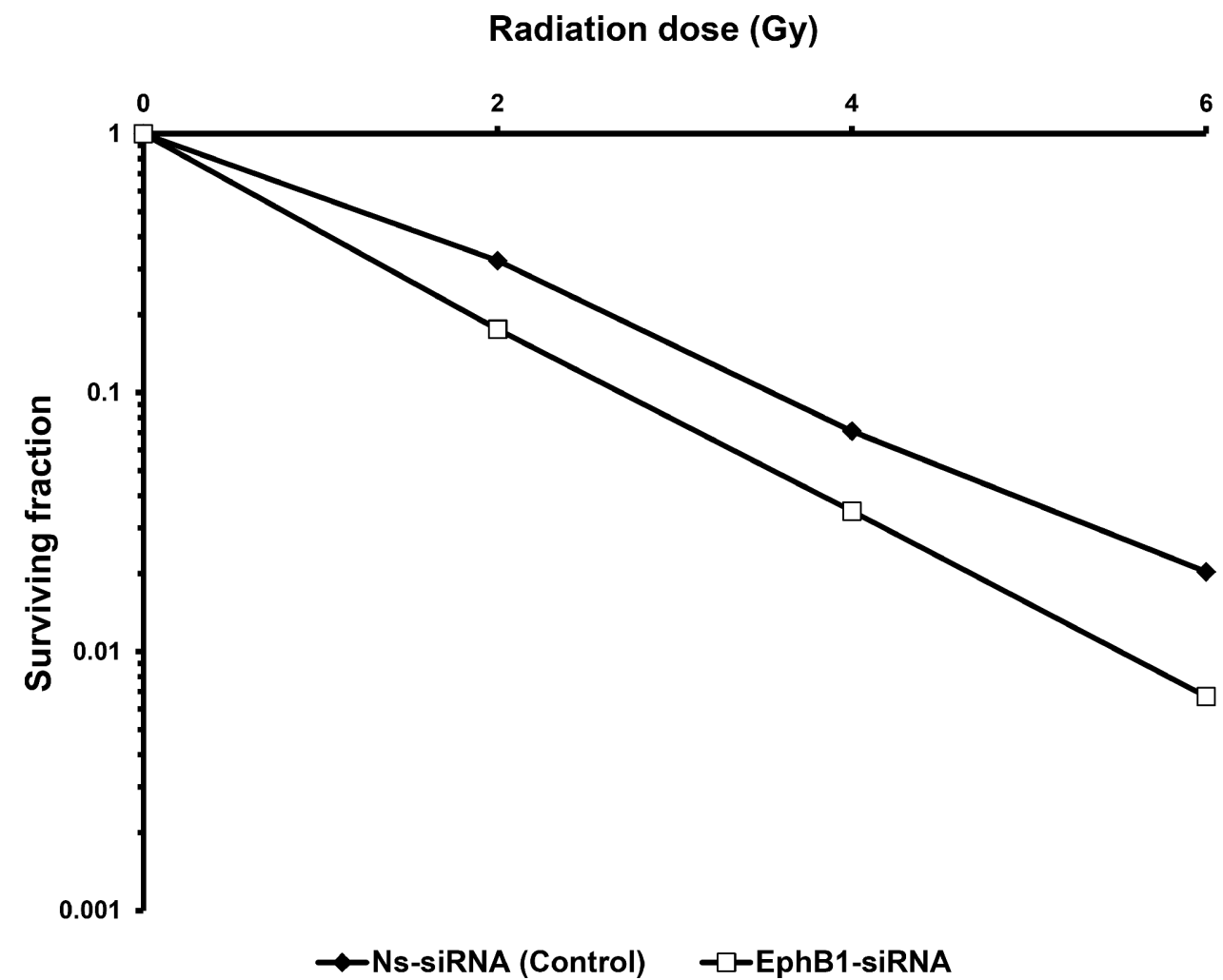

Figure 5: Knockdown of EphB1 receptor sensitizes fibroblasts to ionizing radiation. Survival curves from clonogenic assays comparing ATM-proficient ATCL8 cells transfected with EphB1-targeting siRNA to control transfectants show that EphB1 targeting reduces cell survival.

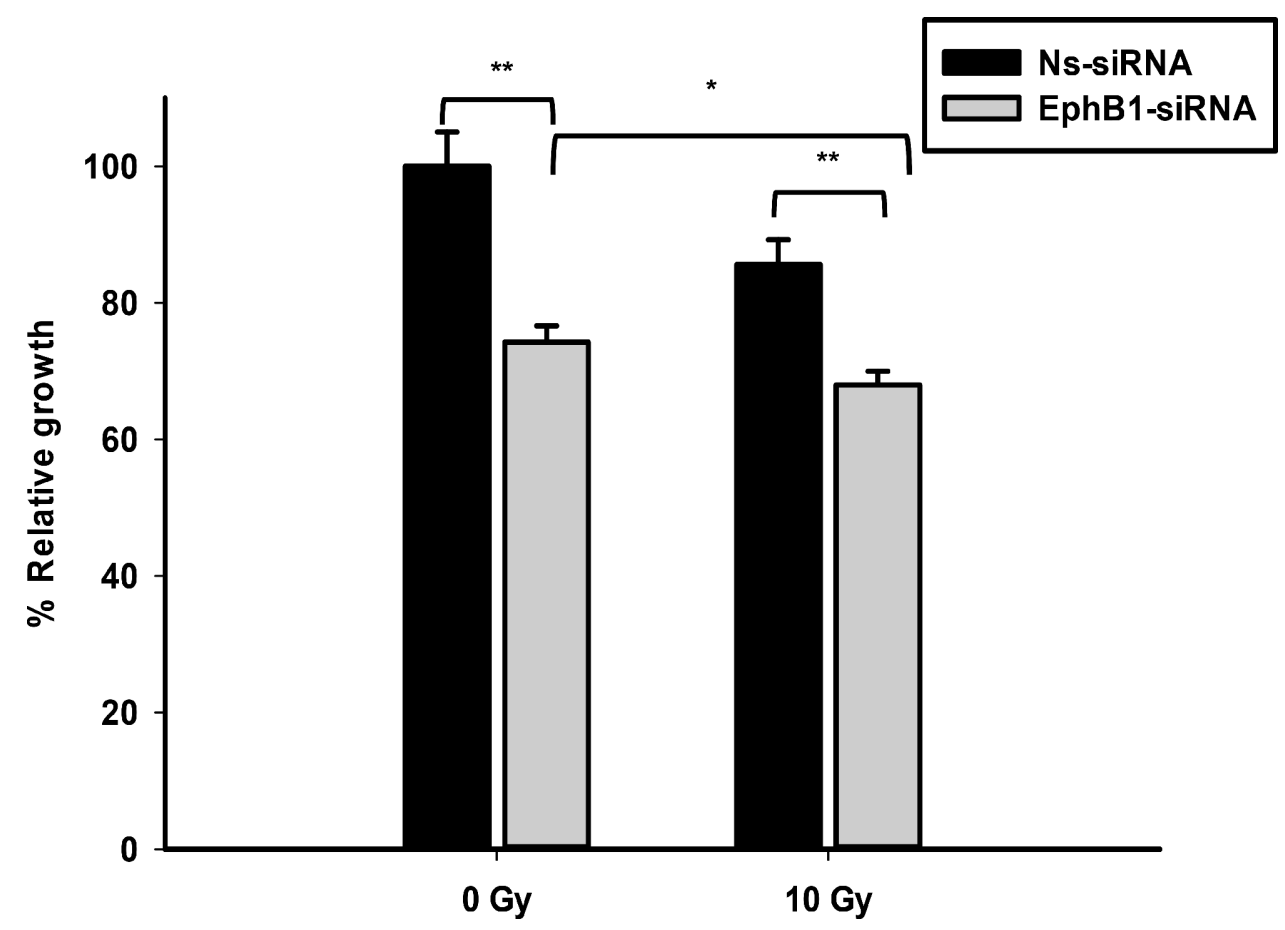

Figure 6: Knockdown of EphB1 receptor sensitizes DAOY cells to ionizing radiation. DAOY cells transiently transfected with either non-specific siRNA (Ns-siRNA) or EphB1-targeting siRNA were irradiated at 24 h post-transfection with 10 Gy. At 96 h posttransfection, MTT reagent was added to samples and optical density measured after $24 \mathrm{~h}$ incubation. Data shown are normalized values and represent average \pm standard error with ${ }^{*} p<0.001,{ }^{*} p<0.05$. 


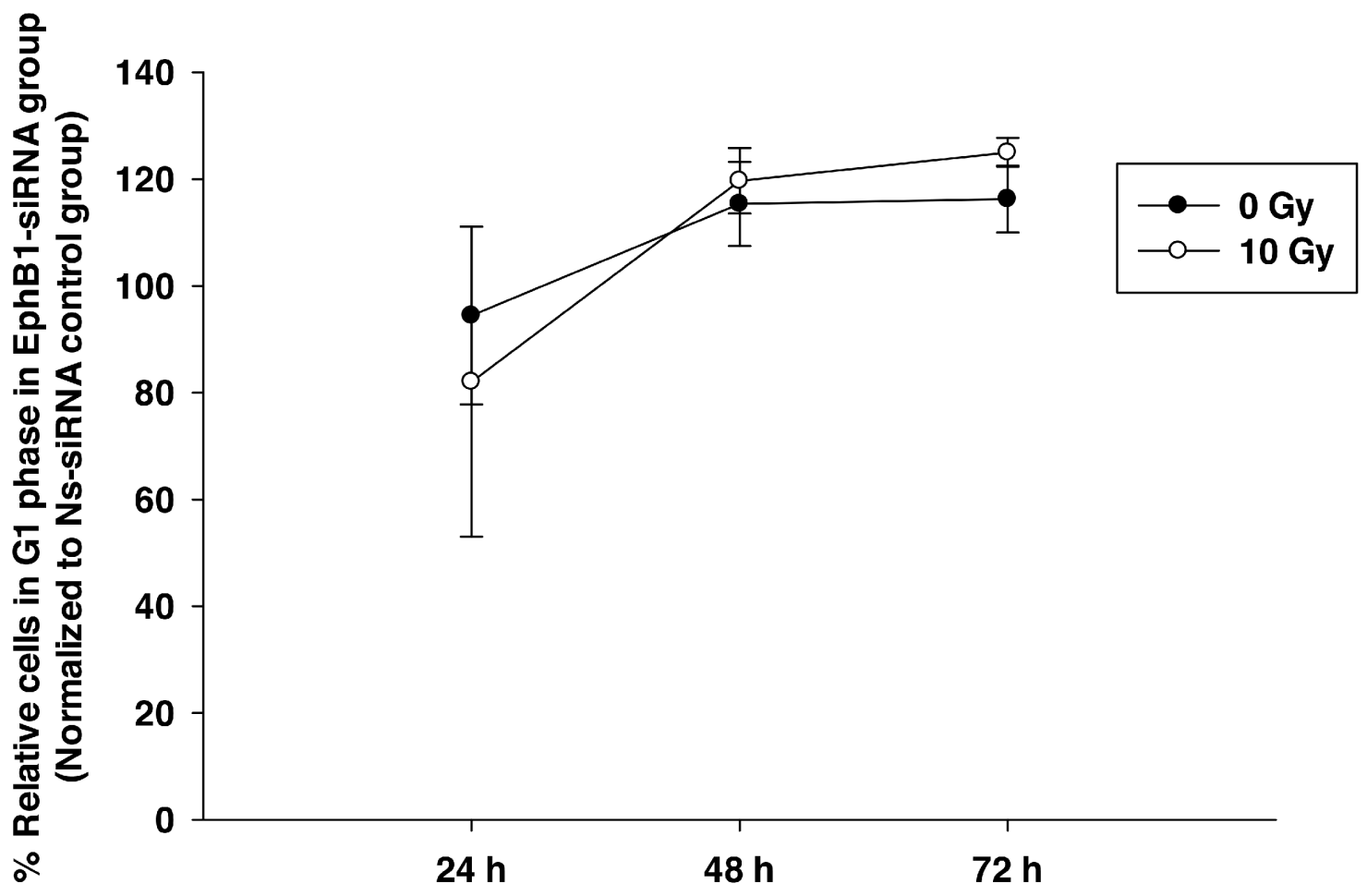

\begin{tabular}{|c|c|c|}
\hline Time-points & $\begin{array}{c}\text { \% Relative cells in } \\
\text { G1 phase in EphB1 } \\
\text { knockdown group } \\
\text { (No XRT) }\end{array}$ & $\begin{array}{c}\text { \% Relative cells in } \\
\text { G1 phase in EphB1 } \\
\text { knockdown group } \\
\text { (10 Gy XRT) }\end{array}$ \\
\hline $\mathbf{2 4} \mathbf{~ h}$ & 94.47 & 82.07 \\
\hline $\mathbf{4 8} \mathbf{~ h}$ & 115.37 & 119.71 \\
\hline $\mathbf{7 2} \mathbf{h}$ & 116.30 & 125.03 \\
\hline
\end{tabular}

Figure 7: Knockdown of EphB1 receptor enhances the percentage of cells in G1 phase in irradiated DAOY cells. DAOY cells were transiently transfected with non-specific siRNA (Ns-siRNA) or EphB1-targeting siRNA and irradiated with 10 Gy at 24 h posttransfection. At 24, 48, and $72 \mathrm{~h}$ post-radiation, cell cycle profiles were assessed by flow cytometry. Data points represent the percentage of G1 cells in EphB1-siRNA treated group (normalized to Ns-siRNA treated group) in the absence and presence of ionizing radiation. Data shown are average \pm standard error for $n \geq 2$ independent experiments. The percentage of EphB1-siRNA treated cells in G1 phase of cell cycle at different time-points are indicated in the tabular format. 
$E p h B 1^{+/+}$Smo

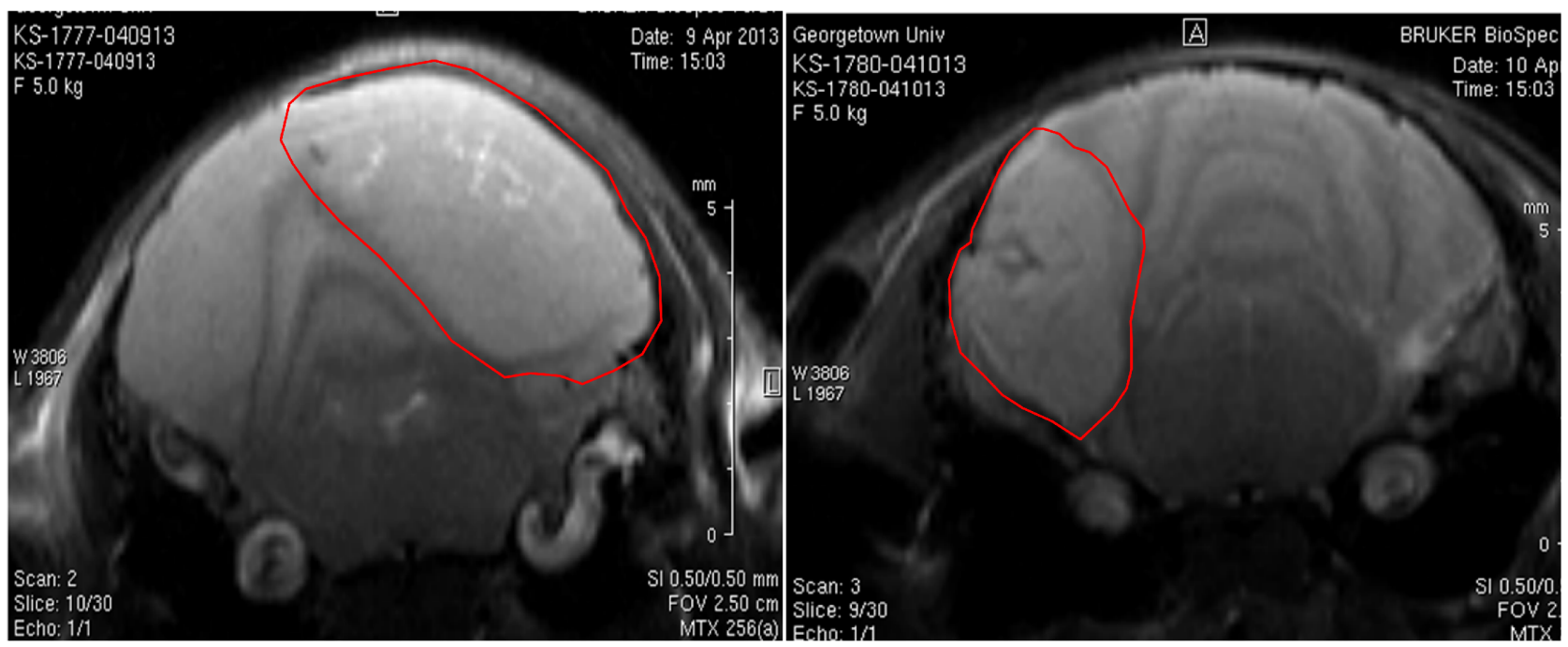

B

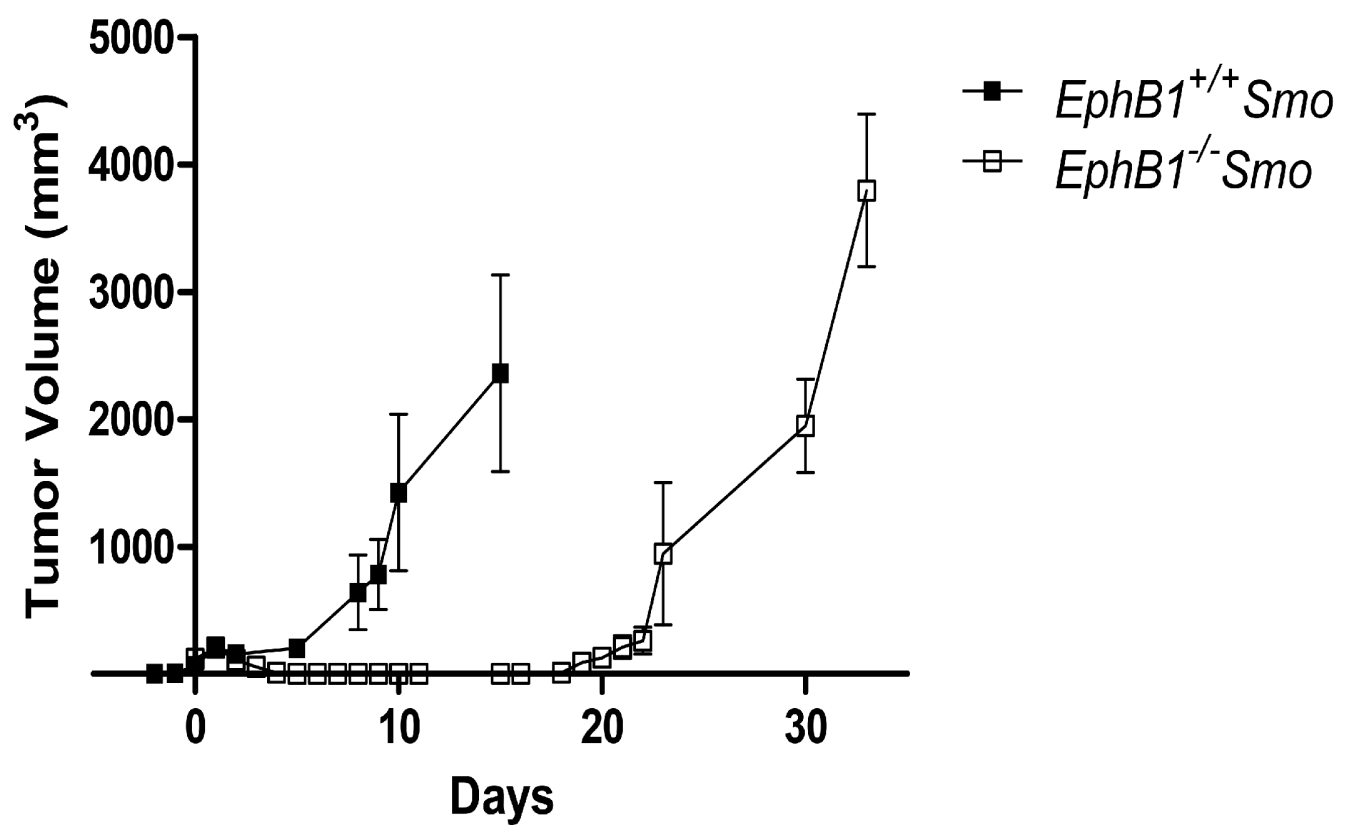

Figure 8: Tumors harvested from EphB1-deficient mice demonstrate enhanced tumor growth delay after irradiation. (A) MRI imaging shows the development of cerebellar medulloblastomas in genetically engineered medulloblastoma mouse model. EphB1 $1^{-1-}$ Smo mice and their EphB1 ${ }^{+/}$Smo littermate controls (age-matched and gender-matched) were followed by serial MRI imaging for target delineation from postnatal day 28 until onset of disease or euthanization $(n=44)$. Representative images are shown

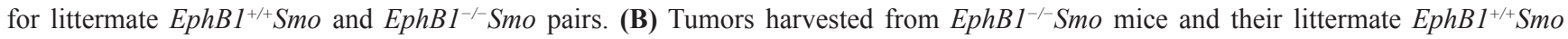
controls were transplanted subcutaneously into the mid-dorsal surface of the mouse just rostral to the tail. Tumor masses harvested from $E p h B 1^{-/-}$Smo mice exhibited a three-fold delay in tumor recurrence compared to tumor masses harvested from littermate EphB1 ${ }^{+/+} \mathrm{Smo}$ controls after fractionated ionizing radiation $(5 \mathrm{~Gy} /$ day $\times 4$ doses $)$ treatment $(p<0.001)$. 
and their ligands in tumor cell survival, invasion, and metastasis [30, 31]. In the present study, we investigated the functions and mechanisms underlying the effects of EphB1 receptor knockdown on cell growth, migration, and radioresistance in medulloblastoma. Our findings indicate that EphB1 downregulation reduces migration and enhances cellular sensitization to radiation therapy by increasing the percentage of cells in the G1 phase of the cell cycle ultimately decreasing medulloblastoma cell growth and viability. Our results are in agreement with published reports suggesting a role of EphB1 in medulloblastoma tumorigenesis [8, 32]. Morrison et al. recently showed that EphB1 transcript levels are significantly upregulated in migrating medulloblastoma cells as compared to non-migrating medulloblastoma cells [8]. EphB1 transcript levels were also found to be significantly upregulated in medulloblastoma tumor spheres with high self-renewing ability compared to tumor spheres with low self-renewing ability [8].

Eph receptor tyrosine kinases and their ephrin ligands have emerged as important players in medulloblastoma tumorigenesis [33]. Infact, microarray data analysis from independent datasets confirm the presence of EphB1 receptor in different clinical medulloblastoma tumor subtypes [34-36]. In a recent study by McKinney et al., it was reported that EphB1 receptor is expressed in different subgroups of medulloblastoma tumors examined [33]. Since, EphB1 is widely expressed in medulloblastoma, we analyzed the expression of EphB1 in human medulloblastoma cell lines DAOY and UW228. These cell lines closely resemble different medulloblastoma subtypes [37]. Our data suggest that both these lines express considerable levels of EphB1 receptor and thus serve as appropriate model systems to study the effects of EphB1 knockdown on radiosensitization in medulloblastoma.

The Eph/ephrin system has been reported to play a key role in cancer cell growth and proliferation. Previous studies report anti-proliferative effects of Eph receptors, mediated primarily by suppression of the ERK/MAPK pathway [29, 38-41]. In contrast, recent findings indicate that some Eph receptors promote cell proliferation, for example in colorectal cancer and in the developing nervous system [30, 42-44]. During development, lack of EphB1 in a mouse model has been reported to significantly reduce the number of neural progenitors in the hippocampus, as well as disrupt the proper migration and organization of neural progenitors [42]. Consistent with these findings, we report that EphB1 knockdown decreases medulloblastoma cell growth and viability. Furthermore, our data provide mechanistic insights into how EphB1 downregulation affects medulloblastoma cell growth and survival (Figure 9). The reduction in the growth and viability of EphB1 knockdown DAOY cells could be explained in part by the decreased expression of cyclin E, a master regulator of cell cycle progression, which in turn results in decreased levels of phosphorylated $\mathrm{Rb}$ and $\mathrm{E} 2 \mathrm{~F} 1$ proteins and also affects the activation of a checkpoint kinase, Chk2, resulting in cell cycle arrest. In addition to playing a regulatory role, overexpression of cyclin $\mathrm{E}$ has been linked to tumorigenesis in different cancers [45]. In view of this, inhibition of cyclin E following EphB1 knockdown likely plays a role in the observed inhibition of medulloblastoma tumor growth. Importantly, the decreased ability of DAOY cells to progress from $\mathrm{G} 1$ to $\mathrm{S}$ phase following EphB1 knockdown, could ultimately be responsible for inhibiting their growth, proliferation, and survival as indicated by reduced expression of PCNA and decreased levels of phosphorylated Akt, and total AKT. Thus, our data clearly underscore the relevance of EphB1 knockdown in inhibiting medulloblastoma cell growth by affecting cell cycle, proliferation, and cell survival pathways. Cross-talk between Eph receptors and other receptor tyrosine kinases has been reported to contribute to malignant cell behavior $[24,31,46]$. The role of EGFR signaling in tumorigenesis is well established [47]. Our results show an appreciable decrease in the levels of phosphorylated EGFR and total EGFR following EphB1-specific siRNA treatment in DAOY cells, suggesting that the EphB1 receptor might be contributing to the metastatic behavior of medulloblastoma cells by functionally interacting with EGFR. This could be relevant in view of the fact that many human cancers have elevated expression of EGFR along with Eph receptors. Thus, targeted therapeutics developed against Eph receptors could potentially be a viable and effective treatment option against EGFR-positive cancers as well.

The role of the Eph/ephrins in cell migration, invasion, and metastasis has been well documented in other tumor models [29]. For instance, downregulation of EphB1 has been shown to reduce migration of neural progenitors in the hippocampus during development [42, 48]. In contrast, enhanced EphB1 signaling has been shown to decrease migration and invasion in glioma cell lines [12]. These different results could be partly explained by the fact that the effect of Eph receptors is highly context-dependent and can vary across different cancer types [29]. Our results indicate that EphB1 knockdown significantly decreases the migratory ability of medulloblastoma cells in culture. This is consistent with previous reports suggesting that EphB1 acts as a pro-migration receptor [25, 26, 49]. Furthermore, our results suggest that downregulation of EphB1 impedes cell migration via alterations in the level of $\beta 1$-integrin and phosphorylated Src. This could be a potential mechanism by which EphB1 contributes to medulloblastoma metastasis. This is in accordance with the study published by HuynhDo et al., wherein the EphB1 ligand, ephrinB1, was found to mediate cell migration through an integrin-dependent pathway [50]. In another study, it was shown that EphB1 regulates cell migration and chemotaxis via stimulation of c-Src activity [26]. Our findings also emphasize the potent role of EphB1 in cancer cell migration.

ATM acts as a key mediator of DNA damage response pathways [27]. It has been reported that ATM regulates 


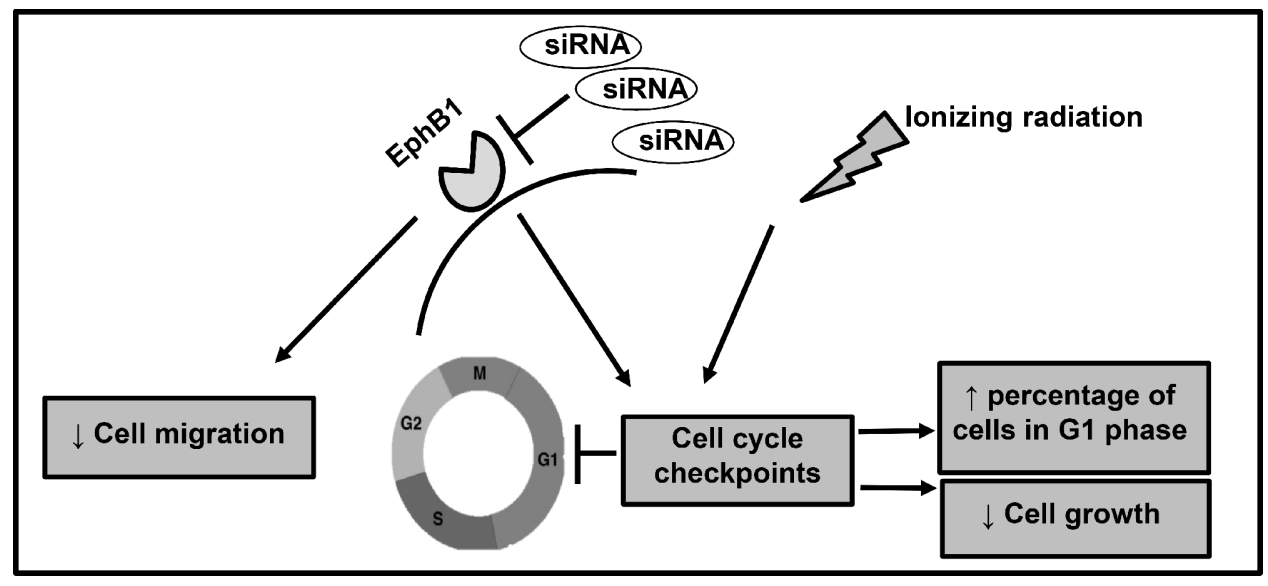

Figure 9: Proposed hypothetical model. EphB1 receptor knockdown radiosensitizes medulloblastoma cells and decreases cell growth, and enhances the percentage of cells in G1 phase of cell cycle. Additionally, siRNA-mediated EphB1 knockdown reduces cell migration.

EphB1 expression [10]. This was validated in fibroblasts, where supplementing wild-type ATM expression in ATMdeficient fibroblasts significantly upregulated EphB1 expression and altered the radiosensitization profile of the cells [10]. In our study, we report that upon EphB1 knockdown, ATM-proficient cells became more sensitive to radiation, thus decreasing survival in clonogenic assays. Other members of the Eph receptor and ephrin families, including EphA2, EphB4, ephrin A1, and ephrin A3, have previously been implicated in radioresistance in different tumor models [51-54]. In line with these studies, we found that siRNA-mediated downregulation of EphB1 receptor modulates the cellular sensitivity of medulloblastoma cells to ionizing radiation in vitro. This was evident in cell cycle analysis where EphB1 knockdown followed by ionizing radiation resulted in an increase in the percentage of DAOY cells in G1 phase of the cell cycle. Given that early G1 is a radioresistant phase of the cell cycle [55], we believe that knockdown of EphB1 forced cells to arrest in late G1 phase, when cells are relatively more sensitive to radiation [55-57]. This in turn affected tumor growth and progression as validated in our experimental model systems. Cells that have a long cycling time, a peak of resistance observed in early G1 phase of cell cycle is followed by a radiosensitive phase toward the end of G1 phase [55]. Other research groups have also shown late G1 cell cycle arrest following treatment with anti-cancer agents and radiation [56, 57]. However, upon further investigating into the mechanism of radiosensitization, we did not observe any significant increase in apoptosis or changes in the levels of apoptotic markers upon EphB1 knockdown. We also performed senescence assays to evaluate the role of EphB1 knockdown on cell senescence. However, we did not see any measurable effect on senescence in our study upon EphB1 receptor downregulation (data not shown). This suggests the involvement of other pathways such as DNA damage repair that might be playing a role in EphB1 knockdown mediated radiosensitization in medulloblastoma cells. Studies are currently underway to support this notion.

Importantly, our data indicate that EphB1 loss enhances radiation sensitivity in vivo as observed in the genetically modified mouse model of medulloblastoma. The transgenic mouse model used in this study has high rate of tumor incidence and it closely resembles the pathological features evident in the human medulloblastoma tumors thus, making it as an important preclinical model system to predict the treatment response. In the present study, we report that the loss of EphB1 did not significantly alter tumor growth in the non-radiated cohort (data not shown). However, tumors that were implanted from $E p h B 1^{--}$Smo mice exhibited a threefold delay in tumor recurrence after fractionated ionizing radiation compared to allografts harvested from $E p h B 1^{+++} S m o$ controls. This is an important finding providing further evidence that EphB1 loss plays a crucial role in enhancing the sensitivity to radiation therapy in medulloblastoma.

In summary, we demonstrate that knockdown of EphB1 receptor decreases medulloblastoma cell growth and migration, increases the number of cells in the G1 phase, and enhances cellular sensitization to ionizing radiation. The influence of EphB1 suppression on medulloblastoma tumorigenesis makes EphB1 a potential candidate for the development of targeted therapies. Thus, therapeutic interventions directed at the EphB1 receptor hold potential in the context of medulloblastoma and other human malignancies.

\section{MATERIALS AND METHODS}

\section{Cell culture and transfection}

The human medulloblastoma cell lines DAOY and UW228 were obtained from the American Type Culture Collection (ATCC, Rockville, MD, USA). The ATM- 
deficient human fibroblast cell line AT5BIVA was obtained from the National Institute of General Medical Sciences (NIGMS). The ATM-proficient human fibroblast cell line ATCL8 was established by transfecting AT5BIVA cells with the wild-type, full-length ATM gene in a pcDNA expression vector. AT5BIVA cells were maintained in modified Eagle's medium with $20 \%$ fetal bovine serum, $100 \mathrm{U} /$ penicillin, and $100 \mathrm{pg} / \mathrm{mL}$ streptomycin. DAOY and UW228 cells were maintained in Dulbecco's Modified Eagle's Medium (DMEM), supplemented with $10 \%$ fetal bovine serum, $1 \%$ penicillin-streptomycin, and $1 \%$ L-glutamine (Life Sciences) at $37^{\circ} \mathrm{C}$ and $5 \% \mathrm{CO}_{2}$. For transfection experiments, sub-confluent DAOY and UW228 cells were transfected in serum-free DMEM using TransIT-TKO Transfection Reagent (Mirus, Madison, WI, USA), according to the manufacturer's instructions. Short interfering RNAs (siRNA) specific for human EphB1 and the non-specific control RNAi were obtained from Invitrogen (Carlsbad, CA, USA). Briefly, cells were transfected using $10 \mu \mathrm{L}$ TransIT-TKO for a final concentration of $25 \mathrm{nM}$ siRNA for migration studies, or $50 \mathrm{nM}$ siRNA for proliferation studies.

\section{Quantitative real-time PCR}

Total RNA was extracted from adherent cells using the RNeasy Kit (Qiagen, Valencia, CA, USA) and reversetranscribed using the High Capacity cDNA Reverse Transcription Kit (Applied Biosystems) according to the manufacturer's instructions. To assess the expression levels of EphB1, quantitative real-time PCR (qRT-PCR) was performed using the TaqMan Gene Expression Assay (Applied Biosystems) on the Applied Biosystems 7900HT Fast Real-Time PCR System, using fast mode. Expression of $\beta$-actin was used to control for RNA loading. Data were analyzed using the comparative cycle threshold (CT) method, as described previously [58].

\section{Whole cell lysate collection}

DAOY cells were homogenized in RIPA lysis buffer (Millipore, MA, USA), containing protease inhibitor cocktail (Thermo Fisher Scientific Inc., IL, USA) and phosphatase inhibitor (Sigma, MO, USA) on ice for 30 min. The homogenate was centrifuged at $4^{\circ} \mathrm{C}$ at 13,000 rpm for $20 \mathrm{~min}$, and the supernatant was collected for analysis of protein expression by western blotting. Protein was quantified using the BCA Protein Assay kit (Thermo Fisher Scientific Inc., IL, USA).

\section{Western blotting and antibodies}

Protein extracts $(20-30 \mu \mathrm{g})$ were loaded onto $10 \%$ SDS-PAGE gels. Electrophoresis, blocking, probing, and visualization of proteins were conducted as described $[59,60]$. Blots were probed overnight at $4{ }^{\circ} \mathrm{C}$ with the respective antibodies. All primary antibodies (anti-EphB1, anti-cyclin E, anti-p-Akt, AKT, anti-p-EGFR, anti-pChk2, p-Src, Src, p-Rb, PARP, Bax, Bcl-XL, and anti$\beta$-actin) were obtained from Cell Signaling Technology (Danvers, MA, USA) except anti-PCNA (BD Biosciences, San Jose, CA, USA), anti-p-E2F1, EGFR (Santa Cruz Biotechnology, Dallas, TX, USA), and anti- $\beta 1$-integrin (Abcam, Cambridge, MA, USA). Horseradish peroxidase (HRP)-conjugated secondary antibodies were obtained from Sigma (St. Louis, MO, USA).

\section{MTT assay}

DAOY cells were seeded at a density of 50,000 cells per well in 24-well plates and maintained in DMEM supplemented with $10 \%$ FBS, $1 \%$ penicillin-streptomycin, and $1 \%$ L-glutamine for $24 \mathrm{~h}$ prior to transfection with siRNA. Subconfluent cells were transfected in serumfree DMEM containing 1\% penicillin-streptomycin and $1 \%$ L-glutamine. At $24 \mathrm{~h}$ after transfection, medium was exchanged for 10\% DMEM supplemented with $1 \%$ penicillin-streptomycin, and $1 \% \mathrm{~L}$-glutamine to stimulate proliferation. The MTT (3-(4, 5-dimethylthiazol-2-yl)-2, 5-diphenyltetrazolium bromide) assay was performed using the Cell Proliferation Kit I (MTT) (Roche Applied Science, Indianapolis, IN, USA). After $48 \mathrm{~h}$ stimulation, $50 \mu \mathrm{L}$ MTT was added to each well and cells were incubated for $4 \mathrm{~h}$ at $37^{\circ} \mathrm{C}$. $250 \mu \mathrm{L} \mathrm{SDS}$ (sodium dodecyl sulfate) was added to dissolve formazan crystals. Cells were incubated for another $24 \mathrm{~h}$ at $37^{\circ} \mathrm{C}$, and optical density was measured on a microplate reader at $550 \mathrm{~nm}$, with a reference filter wavelength of $655 \mathrm{~nm}$. Optical density measurements were compared across control and EphB1-knockdown samples using Student's $t$ test.

\section{Trypan blue dye exclusion}

DAOY cells were seeded at a density of 200,000 cells per well in 6-well plates and maintained in DMEM supplemented with $10 \%$ FBS, $1 \%$ penicillin-streptomycin, and $1 \% \mathrm{~L}$-glutamine for $24 \mathrm{~h}$ before transfection. Cells were transfected in serum-free DMEM, with $1 \%$ penicillin-streptomycin and $1 \%$ L-glutamine. At 24 $\mathrm{h}$ after transfection, medium was exchanged for $10 \%$ DMEM supplemented with $1 \%$ penicillin-streptomycin, and $1 \%$ L-glutamine to stimulate proliferation. After 48 h stimulation, cells were collected by trypsinization. To each $10 \mu \mathrm{L}$ aliquot of cells, $10 \mu \mathrm{L}$ of trypan blue dye was added. Cell counting was performed using the Countess Automated Cell Counter (Life Technologies, NY, USA).

\section{Flow cytometry}

DAOY and UW228 cells were seeded at a density of 200,000 cells per well and 150,000 cells per well respectively in 6-well plates. Cells were maintained in $10 \%$ DMEM supplemented with $1 \%$ penicillin-streptomycin, and $1 \%$ L-glutamine for $24 \mathrm{~h}$ before transfection. Cells 
were transfected using $25 \mathrm{nM}$ (UW228 cells) or $50 \mathrm{nM}$ (DAOY cells) siRNA in serum-free DMEM, with $1 \%$ penicillin-streptomycin and 1\% L-glutamine. At $24 \mathrm{~h}$ after transfection, medium was exchanged for $5 \%$ or $10 \%$ DMEM supplemented with $1 \%$ penicillin-streptomycin, and $1 \%$ L-glutamine to stimulate proliferation. After 48 h stimulation, dead cells were collected by aspirating medium and viable cells were collected by trypsinization. Samples were washed twice in ice-cold PBS, fixed in $70 \%$ ethanol, stained with propidium iodide, and analyzed for cell cycle distribution by fluorescence-activated cell sorting. Data from at least three independent experiments were analyzed by Student's $t$-test.

\section{Electrical impedance-based boyden chamber assay}

The xCELLigence RTCA DP Analyzer (Roche, CA) was used to monitor migration in a CIM-16 plate (ACEA Biosciences). The CIM-16 plate is a modified Boyden chamber in which the porous membrane separating the double-chambered well is coated with gold microelectrodes. In this system, cells migrating from the upper chamber into the lower chamber adhere to these microelectrodes, increasing the electrical impedance across this membrane. Electrical impedance is measured as a "cell index," which directly correlates to the number of cells that have migrated into the lower chamber and adhered to the underside of the membrane. Background measurement was taken by adding cell-free, serum-free DMEM to the upper and lower chambers of each well. The plate was incubated at $37^{\circ} \mathrm{C}$ for $1 \mathrm{~h}$ prior to measuring background electrical impedance for each well. At $48 \mathrm{~h}$ post-transfection, cells were starved for $7 \mathrm{~h}$ in serum-free DMEM supplemented with $1 \%$ penicillin-streptomycin and $1 \%$ L-glutamine, prior to collection by trypsinization. Cells were resuspended in serum-free DMEM with 1\% penicillin-streptomycin and 1\% L-glutamine and seeded in the upper chamber at a density of 50,000 cells per well. Migration was monitored for $24 \mathrm{~h}$. Delta cell index values were calculated by subtracting cell index values in the absence of a serum gradient from cell index values in the presence of a serum gradient. Cell index values between different treatment groups were determined at 30 minute-intervals between 4 and $21 \mathrm{~h}$ after the start of the experiment. Statistical analysis was performed using Student's $t$ test.

\section{Clonogenic survival assay}

Cellular radiation survival was determined following graded doses of 137-Cs radiation. Cells were irradiated in $25 \mathrm{~cm}^{3}$ flasks in exponential phase of growth. Colonies of $>50$ cells were counted 10 to 14 days after plating. Clonogenic cell survival data were fit to the single hit, multi-target and the linear-quadratic models of radiation responses, as described previously $[9,10]$.

\section{In vitro irradiation experiments}

DAOY cells were seeded in 6-well plates at a density of 200,000 cells per well $24 \mathrm{~h}$ prior to transfection, and maintained in 10\% DMEM supplemented with $1 \%$ penicillin-streptomycin, and 1\% L-glutamine for $24 \mathrm{~h}$ before transfection. Cells were transfected in serumfree DMEM, with $1 \%$ penicillin-streptomycin and $1 \%$ L-glutamine. At $24 \mathrm{~h}$ after transfection, cells were irradiated with a one-time radiation fraction of $10 \mathrm{~Gy}$. Cells were incubated at $37^{\circ} \mathrm{C}$ for $24,48 \mathrm{~h}$ and $72 \mathrm{~h}$ after irradiation. At the end of each incubation period, cells were collected for analysis of cell cycle distribution by flow cytometry. MTT analysis was done to determine the effect on cell growth $96 \mathrm{~h}$ post-transfection. Furthermore, the percentage of cells undergoing apoptosis was analyzed following EphB1 knockdown and ionizing radiation exposure $72 \mathrm{~h}$ post-transfection using an Annexin $\mathrm{V}$ detection kit (BD Pharmingen), according to the manufacturer's instructions. Analysis was done by Becton Dickinson FACS Calibur system.

\section{In vivo studies and radiosensitization experiments}

An EphB1 $1^{-/}$Smo medulloblastoma mouse model was generated by breeding the ND2-SmoA1 mouse model (a generous gift from Dr. James Olson, Fred Hutchinson Cancer Research Center, Seattle, WA, USA) to the $E p h B 1^{-1-}$ mouse model [17]. All mice were kept, handled and euthanized in accordance with the ethics guidelines and conditions set and overseen by the Georgetown University Animal Care and Use Committee. The EphB1 $1^{--}$ mice were generated through the homozygous germline mutation of the EphB1 allele [19]. The mice were genotyped as previously described [19]. The presence of the Smo A1 transgene cassette was verified by PCR as described previously [17] and by our group [16, 18]. The EphB1 $1^{-1}$ Smo model therefore lacks EphB1 gene expression and expresses a constitutively activated form of Smoothened (SmoA1) gene in cerebellar granule precursor cells. The $E p h B 1^{+/+} S m o$ mice were used as controls.

Starting at postnatal day 23, tumor development in $E p h B 1^{-/-}$Smo mice and their littermate EphB $1^{+/+} S m o$ controls (both age and gender-matched) was monitored by magnetic resonance imaging (MRI) [18]. Briefly, all MRI procedures were carried out in a 7T Bruker horizontal magnet run by the Paravision 5.1 software at the Georgetown-Lombardi Preclinical Imaging Research Laboratory. Quantitative tumor volumetric analyses were performed essentially as previously described [16, 18, 61]. The mice were anesthetized using $1.5 \%$ isoflurane and $30 \%$ nitrous oxide and positioned inside the magnet using a custom-designed animal holder with temperature and respiration control, which was further adapted to accept a Bruker 4 channel brain array coil. Anatomical MR imaging 
was performed with a two-dimensional T2-weighted RARE (rapid acquisition with relaxation enhancement) protocol with the following parameters: Matrix: $256 \times$ 256, TR: $3500 \mathrm{~ms}$, TE: $36 \mathrm{~ms}$, RARE factor: 8, Averages: 4, FOV: $25 \times 25 \mathrm{~mm}$, and slice thickness: $0.5 \mathrm{~mm}$.

Allograft mouse model. Upon detection of a significant brain tumor mass, transgenic mice were euthanized by $\mathrm{CO}_{2}$ asphyxiation and cervical dislocation, in accordance with guidelines set by the Georgetown University Animal Care and Use Committee. Tumor masses of $100-200 \mathrm{~mm}^{3}$ were resected, placed in $4 \mathrm{ml}$ of cell culture medium, and thoroughly minced. This cell suspension was mixed with Matrigel Matrix (BD Biosciences). For a tumor mass of approximately 200$300 \mathrm{~mm}^{3}, 4 \mathrm{~mL}$ of cell culture medium was used. This suspension was combined with Matrigel at a ratio of 1:3 (v:v) respectively, and $200 \mu \mathrm{L}$ of the suspension was injected subcutaneously into the mid-dorsal surface just rostral to the tail of nude mice.

Tumor masses were allowed to develop and volumetric tumor growth was measured using a caliper. Tumor volume was calculated using the following ellipsoid formula: $(4 / 3)(\pi)$ (width axis radius $\times$ length axis radius $\times$ height axis radius). When tumor masses reached a size of approximately $50-100 \mathrm{~mm}^{3}$, the mice were randomized to control or treated groups and radiation was delivered (5 Gy/day $\times 4$ doses). Tumor growth was monitored for 30 days after completion of radiation treatment. The numbers of tumor bearing mice in each group were: $E \mathrm{phB1} 1^{--} \mathrm{Smo}$ irradiated $(n=16), E p h B 1^{-/}$Smo non-irradiated $(n=$ 16), EphB1 $1^{+/+} S m o$ irradiated $(n=6)$, and $E p h B 1^{+/+} S m o$ non-irradiated $(n=6)$. Statistical significance of EphB1 deficiency on tumor growth curves was assessed using the GraphPad Prism 4.0 software (GraphPad Software, Inc.) by multi-linear regression analysis.

\section{ACKNOWLEDGMENTS}

This work was supported by the Paul Calabresi Career Development Award for Clinical Oncology (K12) and American Cancer Society Institutional Grant (SDK), NIH grant P01CA138390 (EBP), NIH P30 CA51008 (LW) and ABCC (CA and TM). We thank James Olson's laboratory at the Fred Hutchinson Cancer Research Center (Seattle, WA, USA) for providing us with the ND2-SmoA1 medulloblastoma mouse model. We also thank Lisa Hull, Xiumei Zhao, (Department of Biology, Georgetown University, Washington, DC, USA) Xueping Zhang and Alfredo Velena (Department of Radiation Medicine, Georgetown University Medical Center, Washington, DC, USA) for their technical assistance. We thank Sujatha Venkataraman and Dr. Rajeev Vibhakar for helpful discussions and for sharing some of their resources and protocols with us. The MRI imaging was performed in the Lombardi Preclinical Imaging Research laboratory (PIRL), flow cytometry was performed in the Lombardi
Flow Cytometry Shared Resource (FCSR) and University of Colorado Cancer Center Flow Cytometry Shared Resource (FCSR).

\section{CONFLICT OF INTEREST}

The authors declare they have no conflict of interest.

\section{REFERENCES}

1. Pasquale E. Eph receptor signalling casts a wide net on cell behavior. Nature reviews Molecular cell biology. 2005; $6: 462-475$.

2. Janes PW, Adikari S, Lackmann M. Eph/ephrin signalling and function in oncogenesis: lessons from embryonic development. Current cancer drug targets. 2008; 8:473-479.

3. Lisabeth EM, Falivelli G, Pasquale EB. Eph receptor signaling and ephrins. Cold Spring Harbor perspectives in biology. $2013 ; 5$.

4. Salvucci O, Tosato G. Essential roles of EphB receptors and EphrinB ligands in endothelial cell function and angiogenesis. Advances in cancer research. 2012; 114:21-57.

5. Pasquale E. Tumor suppression through bidirectional signaling. Nature reviews Cancer. 2010; 10:165-180.

6. Northcott PA, Jones DT, Kool M, Robinson GW, Gilbertson RJ, Cho YJ, Pomeroy SL, Korshunov A, Lichter P, Taylor MD, Pfister SM. Medulloblastomics: the end of the beginning. Nature reviews Cancer. 2012; 12:818-834.

7. Sikkema AH, den Dunnen WF, Hulleman E, van Vuurden DG, Garcia-Manero G, Yang H, Scherpen FJ, Kampen KR, Hoving EW, Kamps WA, Diks SH, Peppelenbosch MP, de Bont ES. EphB2 activity plays a pivotal role in pediatric medulloblastoma cell adhesion and invasion. Neuro-oncology. 2012; 14:1125-1135.

8. Morrison LC, McClelland R, Aiken C, Bridges $\mathrm{M}$, Liang L, Wang X, Di Curzio D, Del Bigio MR, Taylor MD, Werbowetski-Ogilvie TE. Deconstruction of medulloblastoma cellular heterogeneity reveals differences between the most highly invasive and self-renewing phenotypes. Neoplasia. 2013; 15:384-398.

9. Jung M, Timofeeva O, Cheema AK, Varghese R, Ressom H, Dritschilo A. Human fibroblasts for large-scale "omics" investigations of ATM gene function. Advances in experimental medicine and biology. 2011; 720:181-190.

10. Cheema AK, Timofeeva O, Varghese R, Dimtchev A, Shiekh K, Shulaev V, Suy S, Collins S, Ressom H, Jung M, Dritschilo A. Integrated analysis of ATM mediated gene and protein expression impacting cellular metabolism. Journal of proteome research. 2011; 10:2651-2657.

11. Sheng Z, Wang J, Dong Y, Ma H, Zhou H, Sugimura H, Lu G, Zhou X. EphB1 is underexpressed in poorly differentiated colorectal cancers. Pathobiology : journal of immunopathology, molecular and cellular biology. 2008; 75:274-280. 
12. Teng L, Nakada M, Furuyama N, Sabit H, Furuta T, Hayashi Y, Takino T, Dong Y, Sato H, Sai Y, Miyamoto K, Berens ME, Zhao SG, Hamada J. Ligand-dependent EphB1 signaling suppresses glioma invasion and correlates with patient survival. Neuro-oncology. 2013; 15:1710-1720.

13. Wang JD, Dong YC, Sheng Z, Ma HH, Li GL, Wang XL, Lu GM, Sugimura H, Jin J, Zhou XJ. Loss of expression of EphB1 protein in gastric carcinoma associated with invasion and metastasis. Oncology. 2007; 73:238-245.

14. Hu N, Wang $\mathrm{C}$, Hu Y, Yang HH, Giffen C, Tang ZZ, Han XY, Goldstein AM, Emmert-Buck MR, Buetow KH, Taylor PR, Lee MP. Genome-wide association study in esophageal cancer using GeneChip mapping 10K array. Cancer research. 2005; 65:2542-2546.

15. Karam SD, Burrows RC, Logan C, Koblar S, Pasquale EB, Bothwell M. Eph receptors and ephrins in the developing chick cerebellum: relationship to sagittal patterning and granule cell migration. The Journal of neuroscience : the official journal of the Society for Neuroscience. 2000; 20:6488-6500.

16. Beauchamp EM, Ringer L, Bulut G, Sajwan KP, Hall MD, Lee YC, Peaceman D, Ozdemirli M, Rodriguez O, Macdonald TJ, Albanese C, Toretsky JA, Uren A. Arsenic trioxide inhibits human cancer cell growth and tumor development in mice by blocking Hedgehog/GLI pathway. The Journal of clinical investigation. 2011; 121:148-160.

17. Hatton BA, Villavicencio EH, Tsuchiya KD, Pritchard JI, Ditzler S, Pullar B, Hansen S, Knoblaugh SE, Lee D, Eberhart CG, Hallahan AR, Olson JM. The Smo/Smo model: hedgehog-induced medulloblastoma with $90 \%$ incidence and leptomeningeal spread. Cancer research. 2008; 68:1768-1776.

18. Sirajuddin $\mathrm{P}$, Das $\mathrm{S}$, Ringer L, Rodriguez OC, Sivakumar A, Lee YC, Uren A, Fricke ST, Rood B, Ozcan A, Wang SS, Karam S, Yenugonda V, Salinas P, Petricoin E, 3rd, Pishvaian M, et al. Quantifying the CDK inhibitor VMY-1-103's activity and tissue levels in an in vivo tumor model by LC-MS/MS and by MRI. Cell cycle. 2012; 11:3801-3809.

19. Han Y, Song XS, Liu WT, Henkemeyer M, Song XJ. Targeted mutation of EphB1 receptor prevents development of neuropathic hyperalgesia and physical dependence on morphine in mice. Molecular pain. 2008; 4:60.

20. Liu WT, Han Y, Li HC, Adams B, Zheng JH, Wu YP, Henkemeyer M, Song XJ. An in vivo mouse model of longterm potentiation at synapses between primary afferent C-fibers and spinal dorsal horn neurons: essential role of EphB1 receptor. Molecular pain. 2009; 5:29.

21. Ringer L, Sirajuddin P, Tricoli L, Waye S, Choudhry MU, Parasido E, Sivakumar A, Heckler M, Naeem A, Abdelgawad I, Liu X, Feldman AS, Lee RJ, Wu CL, Yenugonda V, Kallakury B, et al. The induction of the p53 tumor suppressor protein bridges the apoptotic and autophagic signaling pathways to regulate cell death in prostate cancer cells. Oncotarget. 2014.
22. Ringer L, Sirajuddin $\mathrm{P}$, Heckler M, Ghosh A, Suprynowicz F, Yenugonda VM, Brown ML, Toretsky JA, Uren A, Lee Y, MacDonald TJ, Rodriguez O, Glazer RI, Schlegel R, Albanese C. VMY-1-103 is a novel CDK inhibitor that disrupts chromosome organization and delays metaphase progression in medulloblastoma cells. Cancer biology \& therapy. 2011; 12:818-826.

23. Ringer L, Sirajuddin P, Yenugonda VM, Ghosh A, Divito K, Trabosh V, Patel Y, Brophy A, Grindrod S, Lisanti MP, Rosenthal D, Brown ML, Avantaggiati ML, Rodriguez O, Albanese C. VMY-1-103, a dansylated ana$\log$ of purvalanol B, induces caspase-3-dependent apoptosis in LNCaP prostate cancer cells. Cancer biology \& therapy. 2010; 10:320-325.

24. Larsen AB, Pedersen MW, Stockhausen MT, Grandal MV, van Deurs B, Poulsen HS. Activation of the EGFR gene target EphA2 inhibits epidermal growth factor-induced cancer cell motility. Molecular cancer research : MCR. 2007; 5:283-293.

25. Vindis C, Teli T, Cerretti DP, Turner CE, Huynh-Do U. EphB1-mediated cell migration requires the phosphorylation of paxillin at Tyr-31/Tyr-118. The Journal of biological chemistry. :65-70. 2004; 279:27965-27970.

26. Vindis C, Cerretti DP, Daniel TO, Huynh-Do U. EphB1 recruits c-Src and p52Shc to activate MAPK/ERK and promote chemotaxis. The Journal of cell biology. 2003; 162:661-671.

27. Savitsky K, Bar-Shira A, Gilad S, Rotman G, Ziv Y, Vanagaite L, Tagle DA, Smith S, Uziel T, Sfez S, Ashkenazi M, Pecker I, Frydman M, Harnik R, Patanjali SR, Simmons A, et al. A single ataxia telangiectasia gene with a product similar to PI-3 kinase. Science. 1995; 268:1749-1753.

28. Gilad S, Khosravi R, Shkedy D, Uziel T, Ziv Y, Savitsky K, Rotman G, Smith S, Chessa L, Jorgensen TJ, Harnik R, Frydman M, Sanal O, Portnoi S, Goldwicz Z, Jaspers NG, et al. Predominance of null mutations in ataxia-telangiectasia. Human molecular genetics. 1996; 5:433-439.

29. Pasquale EB. Eph receptors and ephrins in cancer: bidirectional signalling and beyond. Nature reviews Cancer. 2010; 10:165-180.

30. Fukai J, Yokote H, Yamanaka R, Arao T, Nishio K, Itakura T. EphA4 promotes cell proliferation and migration through a novel EphA4-FGFR1 signaling pathway in the human glioma U251 cell line. Molecular cancer therapeutics. :268-28. 2008; 7:2768-2778.

31. Brantley-Sieders DM, Zhuang G, Hicks D, Fang WB, Hwang Y, Cates JM, Coffman K, Jackson D, Bruckheimer E, Muraoka-Cook RS, Chen J. The receptor tyrosine kinase EphA2 promotes mammary adenocarcinoma tumorigenesis and metastatic progression in mice by amplifying ErbB2 signaling. The Journal of clinical investigation. 2008; 118:64-78.

32. Gokhale A, Kunder R, Goel A, Sarin R, Moiyadi A, Shenoy A, Mamidipally C, Noronha S, Kannan S, 
Shirsat NV. Distinctive microRNA signature of medulloblastomas associated with the WNT signaling pathway. Journal of cancer research and therapeutics. 2010; 6:521-529.

33. McKinney N, Yuan L, Zhang H, Liu J, Cho YJ, Rushing E, Schniederjan M, MacDonald TJ. EphrinB1 expression is dysregulated and promotes oncogenic signaling in medulloblastoma. Journal of neuro-oncology. 2015; 121:109-118.

34. Kool M, Koster J, Bunt J, Hasselt NE, Lakeman A, van Sluis P, Troost D, Meeteren NS, Caron HN, Cloos J, Mrsic A, Ylstra B, Grajkowska W, Hartmann W, Pietsch T, Ellison D, et al. Integrated genomics identifies five medulloblastoma subtypes with distinct genetic profiles, pathway signatures and clinicopathological features. PloS one. 2008; 3:e3088.

35. Fattet S, Haberler C, Legoix P, Varlet P, LellouchTubiana A, Lair S, Manie E, Raquin MA, Bours D, Carpentier S, Barillot E, Grill J, Doz F, Puget S, JanoueixLerosey I, Delattre O. Beta-catenin status in paediatric medulloblastomas: correlation of immunohistochemical expression with mutational status, genetic profiles, and clinical characteristics. The Journal of pathology. 2009; 218:86-94.

36. Thompson MC, Fuller C, Hogg TL, Dalton J, Finkelstein D, Lau CC, Chintagumpala M, Adesina A, Ashley DM, Kellie SJ, Taylor MD, Curran T, Gajjar A, Gilbertson RJ. Genomics identifies medulloblastoma subgroups that are enriched for specific genetic alterations. Journal of clinical oncology : official journal of the American Society of Clinical Oncology. 2006; 24:1924-1931.

37. Xu J, Margol A, Asgharzadeh S, Erdreich-Epstein A. Pediatric brain tumor cell lines. Journal of cellular biochemistry. 2015; 116:218-224.

38. Kullander K, Klein R. Mechanisms and functions of Eph and ephrin signalling. Nature reviews Molecular cell biology. 2002; 3:475-486.

39. Miao H, Wei BR, Peehl DM, Li Q, Alexandrou T, Schelling JR, Rhim JS, Sedor JR, Burnett E, Wang B. Activation of EphA receptor tyrosine kinase inhibits the Ras/MAPK pathway. Nature cell biology. 2001; 3:527-530.

40. Elowe S, Holland SJ, Kulkarni S, Pawson T. Downregulation of the Ras-mitogen-activated protein kinase pathway by the EphB2 receptor tyrosine kinase is required for ephrin-induced neurite retraction. Molecular and cellular biology. 2001; 21:7429-7441.

41. Bruce V, Olivieri G, Eickelberg O, Miescher GC. Functional activation of EphA5 receptor does not promote cell proliferation in the aberrant EphA5 expressing human glioblastoma U-118 MG cell line. Brain research. 1999; 821:169-176.

42. Chumley MJ, Catchpole T, Silvany RE, Kernie SG, Henkemeyer M. EphB receptors regulate stem/progenitor cell proliferation, migration, and polarity during hippocampal neurogenesis. The Journal of neuroscience : the official journal of the Society for Neuroscience. 2007; 27:13481-13490.
43. Genander M, Halford MM, Xu NJ, Eriksson M, Yu Z, Qiu Z, Martling A, Greicius G, Thakar S, Catchpole T, Chumley MJ, Zdunek S, Wang C, Holm T, Goff SP, Pettersson S, et al. Dissociation of EphB2 signaling pathways mediating progenitor cell proliferation and tumor suppression. Cell. 2009; 139:679-692.

44. Holmberg J, Genander M, Halford MM, Anneren C, Sondell M, Chumley MJ, Silvany RE, Henkemeyer M, Frisen J. EphB receptors coordinate migration and proliferation in the intestinal stem cell niche. Cell. 2006; 125:1151-1163.

45. Dutta A, Chandra R, Leiter LM, Lester S. Cyclins as markers of tumor proliferation: immunocytochemical studies in breast cancer. Proceedings of the National Academy of Sciences of the United States of America. 1995; 92:5386-5390.

46. Vaught D, Chen J, Brantley-Sieders DM. Regulation of mammary gland branching morphogenesis by EphA2 receptor tyrosine kinase. Molecular biology of the cell. 2009; 20:2572-2581.

47. Zandi R, Larsen AB, Andersen P, Stockhausen MT, Poulsen HS. Mechanisms for oncogenic activation of the epidermal growth factor receptor. Cellular signalling. 2007; 19:2013-2023.

48. Bouche E, Romero-Ortega MI, Henkemeyer M, Catchpole T, Leemhuis J, Frotscher M, May P, Herz J, Bock HH. Reelin induces EphB activation. Cell research. 2013; 23:473-490.

49. Han DC, Shen TL, Miao H, Wang B, Guan JL. EphB1 associates with Grb7 and regulates cell migration. The Journal of biological chemistry. 2002; 277:45655-45661.

50. Huynh-Do U, Vindis C, Liu H, Cerretti DP, McGrew JT, Enriquez M, Chen J, Daniel TO. Ephrin-B1 transduces signals to activate integrin-mediated migration, attachment and angiogenesis. Journal of cell science. 2002; 115:3073-3081.

51. Li X, Wang L, Gu JW, Li B, Liu WP, Wang YG, Zhang X, Zhen HN, Fei Z. Up-regulation of EphA2 and downregulation of EphrinA1 are associated with the aggressive phenotype and poor prognosis of malignant glioma. Tumour biology : the journal of the International Society for Oncodevelopmental Biology and Medicine. 2010; 31:477-488.

52. Nojiri K, Iwakawa M, Ichikawa Y, Imadome K, Sakai M, Nakawatari M, Ishikawa K, Ishikawa A, Togo S, Tsujii H, Shimada H, Imai T. The proangiogenic factor ephrinA1 is up-regulated in radioresistant murine tumor by irradiation. Experimental biology and medicine. 2009; 234:112-122.

53. You J, Zhang R, Xiong C, Zhong M, Melancon M, Gupta S, Nick AM, Sood AK, Li C. Effective photothermal chemotherapy using doxorubicin-loaded gold nanospheres that target EphB4 receptors in tumors. Cancer research. 2012; 72:4777-4786.

54. Stahl S, Kaminskyy VO, Efazat G, Hyrslova Vaculova A, Rodriguez-Nieto S, Moshfegh A, Lewensohn R, Viktorsson K, 
Zhivotovsky B. Inhibition of Ephrin B3-mediated survival signaling contributes to increased cell death response of non-small cell lung carcinoma cells after combined treatment with ionizing radiation and PKC 412. Cell death \& disease. 2013; 4:e454.

55. Hall EJ. (2006). Radiobiology for the Radiologist: LWW.

56. Benbrook DM, Shen-Gunther J, Nunez ER, Dynlacht JR. Differential retinoic acid radiosensitization of cervical carcinoma cell lines. Clinical cancer research : an official journal of the American Association for Cancer Research. 1997; 3:939-945.

57. Liu H, Li Y, Raisch KP. Clotrimazole induces a late G1 cell cycle arrest and sensitizes glioblastoma cells to radiation in vitro. Anti-cancer drugs. 2010; 21:841-849.

58. Timofeeva OA, Zhang X, Ressom HW, Varghese RS, Kallakury BV, Wang K, Ji Y, Cheema A, Jung M, Brown ML, Rhim JS, Dritschilo A. Enhanced expression of SOS1 is detected in prostate cancer epithelial cells from
African-American men. International journal of oncology. 2009; 35:751-760.

59. Timofeeva OA, Plisov S, Evseev AA, Peng S, JoseKampfner M, Lovvorn HN, Dome JS, Perantoni AO. Serine-phosphorylated STAT1 is a prosurvival factor in Wilms' tumor pathogenesis. Oncogene. 2006; 25:7555-7564.

60. Timofeeva OA, Gaponenko V, Lockett SJ, Tarasov SG, Jiang S, Michejda CJ, Perantoni AO, Tarasova NI. Rationally designed inhibitors identify STAT3 N-domain as a promising anticancer drug target. ACS chemical biology. 2007; 2:799-809.

61. Fricke ST, Rodriguez O, Vanmeter J, Dettin LE, Casimiro M, Chien CD, Newell T, Johnson K, Ileva L, Ojeifo J, Johnson MD, Albanese C. In vivo magnetic resonance volumetric and spectroscopic analysis of mouse prostate cancer models. The Prostate. 2006; 66:708-717. 